\title{
RNAi-Mediated Down-Regulation of Dicer-Like 2 and 4 Changes the Response of 'Moneymaker' Tomato to Potato Spindle Tuber Viroid Infection from Tolerance to Lethal Systemic Necrosis, Accompanied by Up-Regulation of miR398, 398a-3p and Production of Excessive Amount of Reactive Oxygen Species
}

\author{
Takahiro Suzuki ${ }^{1,2}$, Sho Ikeda ${ }^{1}$, Atsushi Kasai ${ }^{1}$, Akito Taneda ${ }^{3}$, Misato Fujibayashi ${ }^{1}$, \\ Kohei Sugawara ${ }^{1}$, Maki Okuta ${ }^{1}$, Hayato Maeda ${ }^{1} \mathbb{D}$ and Teruo Sano ${ }^{1, *}$ \\ 1 Faculty of Agriculture and Life Science, Hirosaki University, Bunkyo-cho 3, Hirosaki 036-8561, Japan; \\ takahiro.suzuki.ppvd@gmail.com (T.S.); sho.i.hrdi@gmail.com (S.I.); kasaia@hirosaki-u.ac.jp (A.K.); \\ twin.40g.r.grey@gmail.com (M.F.); kohei@t-i-z-z.com (K.S.); okutako3133@yahoo.co.jp (M.O.); \\ hayatosp@hirosaki-u.ac.jp (H.M.) \\ 2 Union Graduate School of Agricultural Sciences, Iwate University, 3-18-8 Ueda, Morioka, \\ Iwate 020-8550, Japan \\ 3 Graduate School of Science and Technology, Hirosaki University, Bunkyo-cho 3, Hirosaki 036-8561, Japan; \\ taneda@eit.hirosaki-u.ac.jp \\ * Correspondence: sano@hirosaki-u.ac.jp
}

Received: 28 February 2019; Accepted: 10 April 2019; Published: 13 April 2019

\begin{abstract}
To examine the role of RNA silencing in plant defenses against viroids, a Dicer-like 2 and 4 (DCL2\&4)-double knockdown transgenic tomato plant line, 72E, was created. The expression of endogenous SIDCL2s and SIDCL4 in line 72E decreased to about a half that of the empty cassette line, EC. When challenged with potato spindle tuber viroid (PSTVd), line 72E showed significantly higher levels of PSTVd accumulation early in the course of the infection and lethal systemic necrosis late in the infection. The size distribution of PSTVd-derived small RNAs was significantly different with the number of RNAs of 21 and 22 nucleotides (nt) in line 72E, at approximately $66.7 \%$ and $5 \%$ of those in line EC, respectively. Conversely, the numbers of $24 \mathrm{nt}$ species increased by $1100 \%$. Furthermore, expression of the stress-responsive microRNA species miR398 and miR398a-3p increased 770\% and $868 \%$ in the PSTVd-infected line 72E compared with the PSTVd-infected EC. At the same time, the expression of cytosolic and chloroplast-localized $\mathrm{Cu} / \mathrm{Zn}$-superoxide dismutase 1 and 2 (SOD1 and SOD2) and the copper chaperon for SOD (CCS1) mRNAs, potential targets of miR398 or 398a-3p, decreased significantly in the PSTVd-infected line 72E leaves, showing necrosis. In concert with miR398 and 398a-3p, SODs control the detoxification of reactive oxygen species (ROS) generated in cells. Since high levels of ROS production were observed in PSTVd-infected line 72E plants, it is likely that the lack of full dicer-likes (DCL) activity in these plants made them unable to control excessive ROS production after PSTVd infection, as disruption in the ability of miR398 and miR398a-3p to regulate SODs resulted in the development of lethal systemic necrosis.
\end{abstract}

Keywords: viroid; pathogenicity; RNA silencing; Dicer-like proteins; small interfering RNA; miR398; miR398a-3p; superoxide dismutase; reactive oxygen species; systemic necrosis 


\section{Introduction}

Viroids are the smallest known pathogens of higher plants [1]. They consist solely of a highlystructured, covalently closed, circular RNA molecule that ranges between 246 and 434 nucleotides (nt) in length. The more than 30 species reported so far are classified into one of two genera, Pospiviroidae or Avsunviroidae, depending on the characteristics of their nucleotide sequence, mode of replication, subcellular localization, host specificity, and specific disease symptoms [2]. Viroids replicate autonomously in the nucleus or chloroplasts of invaded host cells, depending completely on the host's transcription machinery. Some cause mild to severe disease in sensitive hosts, while other infections are asymptomatic. In light of the non-coding nature of the viroid genome, all the factors necessary to replicate in invaded host cells (i.e., to recruit transcription machinery such as RNA polymerase II and transcription factors, to move from cell to cell, and to spread systemically, and even those necessary to cause disease symptoms) must be embedded in the highly base-paired stem-loop structure [3]. However, many of these properties are yet to be studied and described.

Potato spindle tuber viroid (PSTVd) species of the genus Pospiviroid was first identified in North America as the causal agent of spindle tuber disease in potatoes (Solanum tuberosum) [1]. Early studies show that PSTVd has a relatively wide experimental host range [4], and, in the early 21st century, natural infections of PSTVd in hosts other than potato were first reported in tomato and ornamentals of the families Solanaceae and Asteraceae [5-7]. Other pospiviroids in addition to PSTVd have begun to expand into new geographical areas through global distribution of contaminated seeds and vegetatively-propagated planting materials, thereby causing serious concerns in the seed industry, as well as plant quarantine, worldwide [8].

The tomato (Solanum lycopersicum) is the most sensitive host to PSTVd, but the severity of symptoms varies depending on the host cultivar, as well as the PSTVd variant. For example, in response to a severe isolate of PSTVd, symptomatic cultivar 'Rutgers' shows severe leaf curling and stunting, but a tolerant cultivar 'Moneymaker' shows little or no stunting, although both accumulate a systemic abundance of PSTVd $[9,10]$. Such variation in symptoms is believed to be determined by the difference in the genetic makeup of host cultivars in response to the infection of PSTVd variants with distinct molecular characteristics [11].

In response to pathogen attacks, plants induce two layers of defense responses called pathogenassociated molecular patterns (PAMPs)-triggered immunity (PTI) and effector-triggered immunity that involve the activation of various plant defense responses, including programmed cell death [12]. RNA-silencing plays an additional role, functioning to protect many eukaryotic genomes from invading viruses, foreign transgenes, and transposable elements [13-15]. For members of the family Pospiviroidae that replicate inside the nuclei of host cells, double-stranded or highly-structured regions of RNA molecules synthesized during their replication are recognized by RNA silencing, thereby triggering an attack by dicer-like proteins (DCLs), part of the front line of defense that cleaves the replicated RNA into viroid-derived small RNAs (vd-sRNAs) consisting of 21 to 24 nt [9,16-21]. Viroids in the family Avsunviroidae replicate in chloroplasts and are also targeted by DCLs and cleaved into small pieces (around 21 to $22 \mathrm{nt}$ ) [22-24]. Vd-sRNAs are then loaded onto Argonaute (AGO) proteins to form RNA-induced silencing complexes (RISCs), which target native viroid molecules by the guidance of vd-sRNAs and digest them into vd-sRNAs again by slicer activity of AGO proteins [25]. In the meantime, the digested viroid RNA called "aberrant RNA" is speculated to be converted into double-stranded RNA by the action of RNA-dependent RNA polymerase 6 (RDR6) and, again, processed into small pieces by DCLs for the amplification of the silencing signal $[26,27]$. Finally, the action of RNA-silencing mechanism leads to the accumulation of a large quantity of vd-sRNA in viroid-infected host plants, which is thought to play an important role in various aspects of viroid-host interaction, including defense [28-32], molecular evolution, and even symptom expression [33-42].

DCLs play a central role in the RNAi pathway and are key components in the biogenesis of small RNAs (sRNAs), called short interfering RNA (siRNA) and micro RNA (miRNA) [43]. Four DCLs have 
been described in plants: viz., DCL1, DCL2, DCL3, and DCL4 [44]. In Arabidopsis thaliana, DCL1 is involved in miRNA biogenesis and produces mature miRNAs $21 \mathrm{nt}$ in length [45-47].

DCL2 generates stress-related $22 \mathrm{nt}$ natural-antisense-transcript (nat)-siRNAs and $22 \mathrm{nt}$ siRNAs of exogenous origin $[48,49]$ and are reported to process $\sim 22 \mathrm{nt}$ siRNAs from ta-siRNA precursors in the absence of DCL4 [50]. DCL2 (in combination with DCL4) is also involved in the production of secondary siRNAs that trigger a phenomenon known as "transitivity" [51] and play a role in the antiviral defense $[48,52,53]$. DCL3 produces 24 nt-long, DNA repeat-associated siRNAs that guide heterochromatin formation [48]. DCL4 generates $21 \mathrm{nt}$-long siRNAs that mediate post-transcriptional silencing of some endogenous genes (e.g., trans-acting (ta)-siRNAs) [50,54] and of transgenes mediating RNA interference [55]. DCL4 is also responsible for processing specific miRNAs in Arabidopsis thaliana $[56,57]$ and has a role in transcriptional termination $[58,59]$ and antiviral defense mechanisms $[52,60,61]$. Among the various roles of DCL proteins, the action to counteract viruses and viroids is particularly interesting, because they are known to work cooperatively, but hierarchically, to combat pathogens in invaded cells as the front line of defense. In particular, DCL2 and DCL4 play important roles in the defense against viruses $[60,62]$. In addition, DCL1 has the potential to produce 21 nt viral siRNA in the absence of DCL2, DCL3, and DCL4 [52,60].

Published data on the detection of vd-sRNAs in viroid-infected plants suggest that the highly base-paired stem-loop structure of viroids can serve as a substrate for multiple DCLs [9,16-19,22]. Direct evidence for such cleavage was first obtained from experiments demonstrating that PSTVd RNA was cleaved into small pieces of approximately $21 \mathrm{nt}$ in length when incubated with Arabidopsis spp. cell extracts containing DCL activities [18]. A more detailed analysis using a series of Nicotiana benthamiana $D C L$-knockdown lines revealed that PSTVd levels dropped when either (i) DCL4 expression alone was suppressed, or (ii) DCL1, DCL2, or DCL3 were knocked down together with DCL4. These observations led to a new hypothesis, that the combined activity of DCL2 and DCL3 is crucial in the defense against PSTVd $[20,21]$. In this scenario, DCL4 is proposed to play the key role in processing PSTVd, and its activity may obscure or suppress the effects of DCL2/DCL3 on viroid infectivity, suggesting that hierarchical interactions among DCLs are also important in the defense against viroids.

To analyzes PSTVd pathogenicity in tomato plants from the standpoint of RNA silencing, we introduced an inverted-repeat (IR) chimera gene construct, consisting of parts of the tomato SIDCL2a and SIDCL2b genes, which are highly conserved among all four SIDCL2s, and SIDCL4 into the tomato variety 'Moneymaker'. We then challenged three lines of T3-generation plants by inoculating them with PSTVd to examine the roles of DCL2 and DCL4 in the defense against viroid infections. In one of these lines (named line 72E), endogenous SIDCL2s and SIDCL4 mRNAs were down-regulated by transgene-derived RNA silencing, the response to PSTVd infection was changed from "tolerant" to "highly susceptible," and infected plants displayed lethal systemic necrosis. Both deep sequencing analysis and RNA gel-blot hybridization revealed that the size distribution of vd-sRNAs had changed dramatically in PSTVd-infected 72E plants (designated PSTVd-72E), indicating that the defensive capability of DCL2s and 4 against viroid infection was largely impaired. Further analysis revealed that PSTVd infection induced the stress-responsive microRNA species miR398 and miR398a-3p, and that their expression levels were unusually high in PSTVd-72E plants showing necrosis. In response to this, the expression level of mRNAs for cytosolic $\mathrm{Cu} / \mathrm{Zn}$-superoxide dismutase 1 (i.e., SISOD1 and SISOD2 in tomatoes), chloroplast-localized $\mathrm{Cu} / \mathrm{Zn}$-SOD2 (i.e., SISOD3 in tomatoes), and the copper chaperon for SOD (CCS1; i.e., SISOD4 in tomatoes), potential targets for miRNA398, 398a-3p, and 398, respectively, declined greatly. Since SODs, including CCS1 in concert with miR398 and miR398a-3p [63], have a function in controlling the detoxification of harmful reactive oxygen species (ROS) in the cells, their regulation is very important if plants are to tolerate oxidative stresses. In this article, we will present data showing that RNAi-mediated down-regulation of DCL2s and DCL4 results in failed initial defenses against viroid infections, triggers excessive production of ROS by the abnormal expression of miR398 and miR398a-3p regulating SODs, and ultimately results in the development of severe systemic necrosis. 


\section{Materials and Methods}

\subsection{Generation of DCL2/4i Transgenic Tomato 'Moneymaker' Lines}

In order to knockdown DCL2 and DCL4 expression via RNAi, an IR sequence was constructed as follows, based on the sequence of tomato homologs of A. thaliana DCL2 (SIDCL2a, Solyc06g040960; SIDCL2b, Solyc11g008540; SlDCL2c, Solyc11g008520; SIDCL2d, Solyc11g008530) and DCL4 (SIDCL4, Solyc07g005030) registered in the tomato genome database (https://solgenomics.net/organism/Solanum lycopersicum/genome). The artificial chimera gene (SlartDCL2\&4) was constructed by placing parts of SIDCL2a (277 bp), SIDCL2b (288 bp), and SIDCL4 (300 bp) in head-to-head orientation across an intron sequence to create an IR sequence (Figure 1). As shown in the figure, the sequences of S1DCL2a and $S 1 D C L 2 b$ used were selected from regions having high homology with the other S1DCL2s sequences to simultaneously knock down all the four S1DCL2s. SlartDCL2\&4 IR was inserted into the SacII/SalI site of pBluescript II SK (+) plasmid (Agilent Technologies, Tokyo, Japan), re-cloned into the BglII/KpnI site of binary vector pIG121-Hm [64] downstream of the CaMV-35S promoter (35S:SlartDCL2\&4 IR), and introduced into Agrobacterium tumefaciens strain EHA105 to transform tomato cv 'Moneymaker' by the leaf disc method [28]. Transformants (T0 generation) were selected on media containing kanamycin, transplanted to pots for further cultivation, and self-fertilized to produce the T1 generation. By repeating the kanamycin selection and self-fertilization, three lines (hpDCL2/4i-51-6, -72E, and -82a) of the T3-generation were selected. In addition, tomato plants transformed with pIG121-Hm containing an empty cassette were created and used as a negative control (line EC).

\subsection{Preparation of PSTVd Inoculum and Infection Assay}

Plasmid DNA $(\sim 2 \mu \mathrm{g})$ containing an infectious cDNA clone of PSTVd-Intermediate (pTZ18R-Rz6-PSTV; accession number M16826) was linearized by NotI restriction enzyme digestion (Takara Bio, Otsu, Shiga, Japan) and used for in vitro transcription in a $20 \mu \mathrm{L}$ reaction mixture containing T7 RNA polymerase (Invitrogen, Carlsbad, CA, USA) at $37^{\circ} \mathrm{C}$ for $2 \mathrm{~h}$ according to manufacturer's instruction. Inoculum was adjusted to a concentration of $100 \mathrm{ng}$ of the transcript $/ \mu \mathrm{L}$ in $50 \mathrm{mM}$ sodium phosphate buffer ( $\mathrm{pH} 7.5), 1 \mathrm{mg} / \mathrm{mL}$ bentonite. For mechanical inoculation, an aliquot $(10 \mu \mathrm{L})$ was placed on the third true leaf of 'Moneymaker' seedlings dusted with carborundum (600-mesh) and gently rubbed against the leaf 10-times using a sterile glass-bar. Ten seedlings each from four different hpDCL2/4i Moneymaker lines (i.e., EC, 51-6, 72E and 82a) were used for each infection assay. After inoculation, plants were incubated in a growth chamber controlled at $22{ }^{\circ} \mathrm{C}$ (night) $-30{ }^{\circ} \mathrm{C}$ (day), 16-h day-length supplemented with high-intensity fluorescent light (40 watts $\times 4$ ).

\subsection{Preparation of Total Nucleic Acids, Genomic DNA, and Total RNA from Tomato Plants}

The accumulation of viroids in the inoculated plants was examined using total nucleic acids extracted by the CTAB method [65]. Two leaf disks ( $1 \mathrm{~cm}$ in diameter, $\sim 0.05 \mathrm{~g})$ were collected from the uppermost expanded leaves of each plant at two, three, and four weeks post inoculation (wpi), and homogenized in $0.5 \mathrm{~mL}$ of $2 \times \mathrm{CTAB}$ buffer using a multi-specimen cell disruption device (Shake Master, BMS Co Ltd., Tokyo, Japan) with two zirconia-balls $(\varphi=5 \mathrm{~mm}$ ). Total nucleic acid pellets were dissolved in $50-100 \mu \mathrm{L}$ distilled water.

The presence and the copy number of transgene were examined by detecting the CaMV-35S promoter sequence in genomic DNA preparations extracted from samples of leaf tissue. Total nucleic acids were extracted from homogenate prepared in $2 \times$ CTAB buffer $(\sim 1 \mathrm{~g} / 5 \mathrm{~mL})$ with an equal volume $(v / v)$ of phenol-chloroform (1:1), precipitated by ethanol, and resuspended in 100-400 $\mu \mathrm{L}$ distilled water. They were further incubated with RNaseA (DNase-free, Wako NIPPON GENE, Japan) at $37^{\circ} \mathrm{C}$ for $45 \mathrm{~min}$ ( $\mathrm{min}$ ) to digest RNAs, and ethanol-precipitated after extraction with phenol-chloroform. RNA-free genomic DNA pellets were dissolved in $100 \mu \mathrm{L}$ distilled water.

Total RNA preparations required for analysis of transgene transcripts, siRNA derived from transgene transcripts, small RNAs for deep sequencing, and specific host gene expression, were 
extracted using Trizol (Thermo Fisher Scientific, Tokyo, Japan) or TriReagent (Molecular Research Center, Inc., Cincinnati OH, USA) according to the manufacturer's instruction.

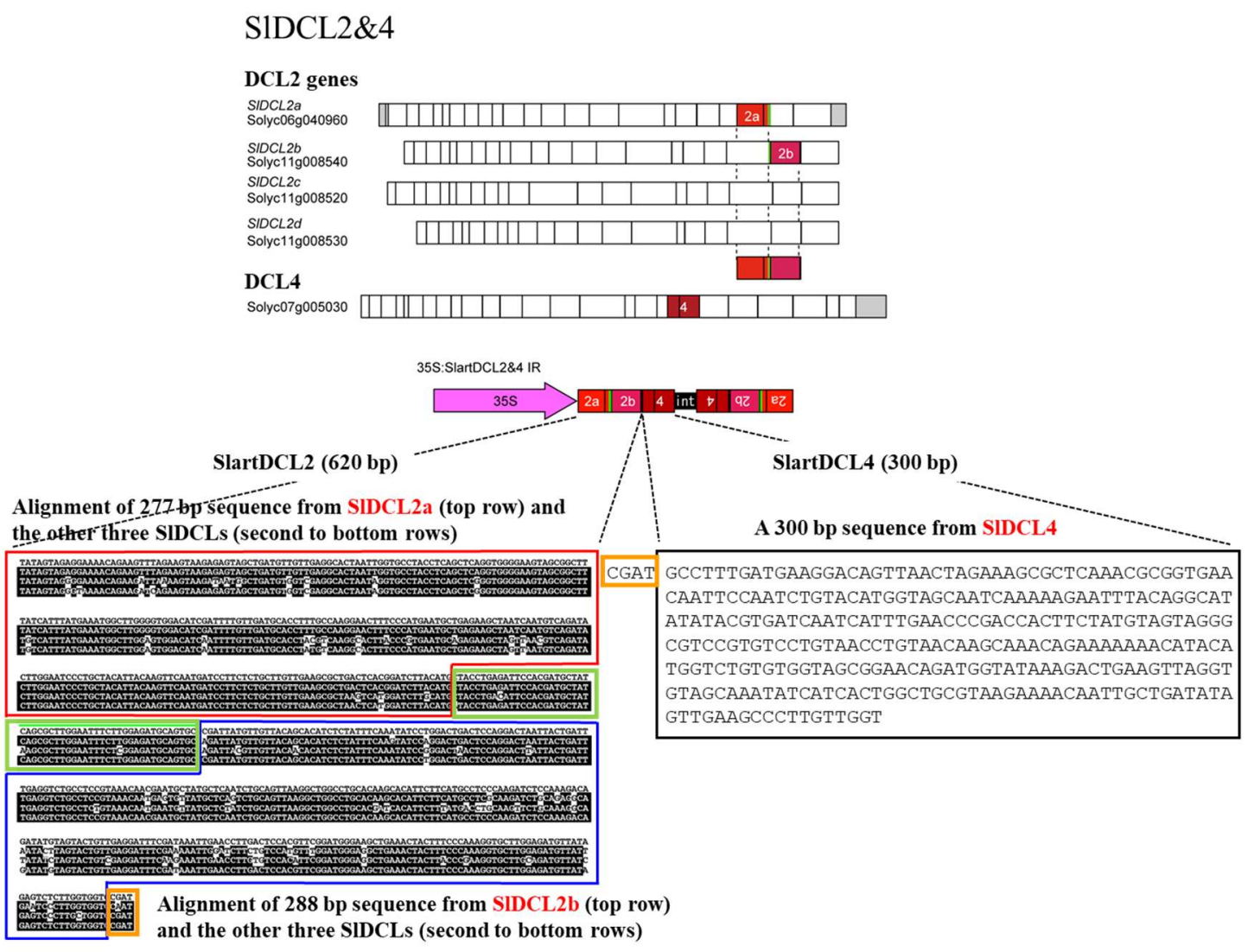

Figure 1. Schematic diagram of the artificial chimera gene (SIDCL2\&4). Based on the alignment of four tomato DCL2 genes (SIDCL2a, $b, c, d)$ and one DCL4 gene (SIDCL4) sequences registered in the database, two regions from SIDCL2, i.e., one from SIDCL2a $(277 \mathrm{bp})$ and the other from SIDCL2b (288 bp), and one region from SIDCL4 (300 bp), as shown in the top of the figure, were selected. An artificial chimera gene composed of the three sequences from SIDCL2a (top row in the red box), SIDCL2b (top row in the blue box), and SIDCL4 (in the black box) was created. The sequences in the second to fourth rows in the red box indicate the corresponding sequences of $\operatorname{SIDCL} 2 b, 2 c$, and $2 d$, respectively. The nucleotide with the black background shows the one that is the same as the SIDCL2a sequence. Similarly, those in the second-fourth in blue indicate the sequences of SIDCL2a, $2 c$, and $2 d$, respectively. The sequence boxed in green is a region with a common sequence between SIDCL2a and $2 b$, and that in orange is a sequence common to those of SIDCL2b and 4. A pair of the chimera gene construct were then placed in head-to-head orientation across an intron sequence ('int' in the figure) to create an IR sequence. SlartDCL2\&4 IR was inserted into the SacII/SalI site of pBluescript II SK (+) plasmid, re-cloned into the $B g l \mathrm{II} / \mathrm{KpnI}$ site of binary vector pIG121-Hm downstream of the CaMV-35S promoter (35S:SlartDCL2\&4 IR), and introduced into Agrobacterium tumefaciens strain EHA105 to transform tomato cv. 'Moneymaker' by the leaf disc method.

\subsection{Detection of CaMV-35S Promoter Sequence by PCR}

Portions of the CaMV-35S promoter and actin gene sequences were amplified by PCR using $0.1 \mu \mathrm{g}$ of total nucleic acids as a template and analyzed by $7.5 \%$ polyacrylamide gel electrophoresis (PAGE). PCR was performed using One Taq DNA polymerase (New England BioLabs, Japan) according to the manufacturer's instruction and the appropriate primer set (see Table S1). The resulting PCR products were fractionated in 7.5\% PAGE containing $1 \times$ TAE buffer. 


\subsection{Southern-blot Hybridization to Analyse Transgene Copy Number in Transformed Plants}

Aliquots of genomic DNA ( 15 $\mu \mathrm{g})$ were digested with EcoRI or BamHI (Thermo Fisher Scientific K.K., Japan), electrophoresed at $50 \mathrm{~V}(4 \mathrm{~V} / \mathrm{cm})$ for $8 \mathrm{~h}$ in $1.0 \%$ agarose gel $(1 \times \mathrm{TAE}$ buffer), transferred to a nylon membrane (Biodyne; Pall Corporation, Port Washington, NY, USA) after $\mathrm{NaOH}$-denaturation followed by HCl-neutralization, and hybridized with a DIG-labeled cRNA probe for CaMV-35S promoter sequence. Hybridization signals were visualized using Chemidoc-XRS imaging system and quantified using the Quantity One (version 4.6.2) software package.

\subsection{Northern-Blot Hybridization to Analyse Transgene Transcripts, Sirna Derived from Transgene Transcripts, Vd-Srnas, and Mirna}

Total RNA preparations (1 10 $\mu \mathrm{g}$ ) extracted using Trizol or TriReagent were denatured by heating for $15 \mathrm{~min}$ at $68{ }^{\circ} \mathrm{C}$ in a solution containing $50 \%$ formamide (for transgene transcripts and host gene expression) or $50 \%$ urea (for siRNA derived from transgene transcripts, viroid-specific small RNAs, and miRNA), fractionated in $1.2 \%$ agarose gels containing $1 \times$ MOPS buffer at $50 \mathrm{~V}$ for $\sim 30 \mathrm{~min}$ (for transgene transcripts and host gene expression) or $12 \%$ polyacrylamide (acrylamide:bisacrylamide $=19: 1$ ) gels containing $1 \times$ TBE-8M urea at $450 \mathrm{~V}$ for $\sim 60 \mathrm{~min}$ (for siRNA derived from transgene transcripts, viroid-specific small RNAs, and miRNA), transferred to a nylon membrane (Biodyne), and hybridized with DIG-labeled cRNA probes for IR-DCL2/4 transcript, PSTVd, and miR398a-3p (5'-UAUGUUCUCAGGUCGCCCCUG-3').

\subsection{RT-qPCR Analysis of Endogenous DCLs, SODs, and miR398a-3p Expression Levels}

Total RNA was extracted using TRizol reagent (Invitrogen, USA), and treated with TURBO DNA-free (Applied Biosystems, Ambion, USA). In accordance with the manufacturer's instructions, cDNA was synthesized from $1 \mu \mathrm{g}$ RNA as a template using Superscript VILO (Invitrogen). qPCR analysis was performed essentially as described in Kasai et al. (2013) [31] using SsoFastEvaGreen Supermix (Bio-Rad) with a Chrome4 real time PCR detector (Bio-Rad). Information used to design the PCR primers for tomato DCL1, DCL2s, DCL3, and DCL4 genes was obtained from the EMBL database. The PCR primers for tomato cytosolic $\mathrm{Cu} / \mathrm{Zn}$-SOD1 (i.e., SISOD1 and SlSOD2), chloroplast-localized $\mathrm{Cu} / \mathrm{Zn}-\mathrm{SOD} 2$ in (i.e., SISOD3), and copper chaperon for superoxide dismutase CCS1 (i.e., SISOD4) were those reported in Feng et al. [66]. The RT-qPCR results were normalized to an actin gene, because in our preliminary examinations, the gene was most stably expressed in our experimental conditions during the observation period. The primers used for $\mathrm{qPCR}$ are described in Table S1. For the analysis of miR398a-3p by RT-qPCR, stem-loop reverse transcription followed by TaqMan PCR analysis [67] were applied using primers and probes listed in Table S1.

\section{8. sRNA Preparation and Deep Sequencing Analysis of PSTVd-Derived sRNAs}

Samples of leaf tissue (a total of $\sim 1 \mathrm{~g}$ ) were collected from two leaves each (leaves 5 and 6 showing yellowing and necrosis) from three plants each (i.e., a total of six leaf tissues) of line 72E and EC infected with PSTVd at three wpi. Total RNAs extracted by Trizol were quantified by UV spectrophotometry and sent aliquots (ca. $50 \mu \mathrm{g}$ ) to Hokkaido System Science Co., Ltd. (Sapporo, Japan) for small RNA sequence analysis (2Gb scale, paired end) on an Illumina HiSeq (Illumina, San Diego, CA, USA). Samples were quantified and their integrities verified using an Agilent 2100 Bioanalyzer (Agilent Technologies, Santa Clara, CA, USA), and processed using a TruSeq small RNA Library Prep Kit.

Adapter sequences were removed from the ends of the resulting raw short-read data based on the presence of an exact $10 \mathrm{nt}$ match with the termini of the respective adapters, and identical short reads were grouped according to read size (15-45 nt). In this way, adapter-trimmed short read data was converted to a non-redundant and also a redundant "short-read-sequence occurrence" format. The redundant data allowing a maximum of $1 \mathrm{nt}$ mismatch were then mapped to either the genomic or anti-genomic strand of the circular form of PSTVd genome using hssmap, a specially-written C 
language program to process the data. The non-redundant data, on the other hand, were used for host small RNA analysis including miRNAs after normalization to the number of reads per million reads.

MiRNA analysis was performed manually using the latest miRbase (Release 21). A list of sequences that includes precursor miRNAs together with annotations for mature regions in miRNA was downloaded from miRbase (http://www.mirbase.org/).

\subsection{ROS Production and Scavenging Activity Assay}

The generation of ROS was analyzed by quantitating hydrogen peroxide using a commercial kit Radical catch (Hitachi Ltd., Tokyo, Japan). Briefly, a leaflet (ca. $0.2 \mathrm{~g}$ ) was homogenized in $1 \mathrm{~mL}$ of $0.1 \mathrm{M}$ sodium phosphate buffer ( $\mathrm{pH} 7.0$ ) and centrifuged at 13,000 rpm for $5 \mathrm{~min}$ to collect the supernatant. According to the manufacturer's instructions, an aliquot of the supernatant $(10 \mu \mathrm{L})$ was mixed with a mixture of $5 \mathrm{mM}$ of cobalt chloride solution (Reagent A; $25 \mu \mathrm{L}$ ) and luminol solution (Reagent B; $25 \mu \mathrm{L}$ ), and reacted for $120 \mathrm{~s}$ (s) to measure the amount of luminescence emission in an incubator (AccuFLEX Lumi400; Hitachi Ltd., Tokyo, Japan). Sample luminescence and the control luminescence were obtained by subtracting the measured value of $80 \mathrm{~s}$ from that of $120 \mathrm{~s}$. Homogenization buffer was used for control. Statistical analysis was performed using R software.

ROS scavenging activity was analyzed by quantitating hydrogen peroxide scavenging activity using the same kit. Briefly, the supernatant obtained above was further diluted 50-times with the same buffer. According to the manufacturer's instructions, an aliquot of the diluted supernatant $(10 \mu \mathrm{L})$ was mixed with a mixture of $5 \mathrm{mM}$ of cobalt chloride solution (Reagent $\mathrm{A} ; 25 \mu \mathrm{L}$ ) and luminol solution (Reagent $\mathrm{B} ; 25 \mu \mathrm{L}$ ), and incubated at $37^{\circ} \mathrm{C}$ for $5 \mathrm{~min}$. The mixture was further added by hydrogen peroxide solution (1:1000-diluted Reagent $C ; 25 \mu \mathrm{L}$ ) and reacted for $120 \mathrm{~s}$ to measure the amount of luminescence emission. Sample luminescence and the control luminescence were obtained by subtracting the measured value of $80 \mathrm{~s}$ from that of $120 \mathrm{~s}$. Homogenization buffer was used for control. Hydrogen peroxide scavenging activity was calculated using the following equation; i.e., Hydrogen peroxide scavenging activity $(\%)=\{$ Luminescence $($ Control $)-$ Luminescence $($ Sample $)\} /$ Luminescence $($ Control $) \times 100$. Statistical analysis was performed using $R$ software.

\section{Results}

\subsection{Characterization of DCL2/4-Knockdown Transgenic Tomato Lines}

The hairpin RNA produced by transcription of the SlartDCL2\&4 IR transgene in tomato cells should activate the RNAi machinery, induce the production of siRNAs complementary to SIDCL2a, SIDCL2b, and SIDCL4 transcripts, and suppress endogenous SIDCL2s and SIDCL4 expression. To assess the effects of transgene expression, we first verified the presence of transgene, the transgene copy number, the expression level of transgene transcript, and the accumulation of siRNAs derived from the transgene transcript in the three lines selected for the study.

Presence of the transgene was examined by PCR amplification of CaMV-35S promoter sequence from genomic DNA extracted from transgenic lines. As a result, an amplicon of approximately $900 \mathrm{bp}$, the size expected from the primer set used, was detected from all the three lines of hpDCL2/4i (Figure S1a).

The transgene copy number was assayed by Southern-blot hybridization using a DIG-labeled cRNA probe for the CaMV-35S promoter. From line 51-6, two bands were detected in an EcoRI-digest, and one band in the corresponding BamHI digest, indicating that this line contains two copies. From line 72E, one band was detected in both the EcoRI and BamHI digests, indicating that this line contains a single copy. Multiple (5-6) bands were detected in both the EcoRI and BamHI digests of line 82a, indicating that this line contains multiple copies of the transgene (Figure S1b).

Transgene transcripts were assayed using Northern hybridization with a DIG-labeled cRNA probe for SlartDCL2\&4. A dense positive signal was detected from $1 \mu \mathrm{g}$ of total RNA in line 72E, indicating the accumulation of high levels of transgene transcript. On the other hand, the signal was virtually 
invisible in samples from lines 82a and 51-6 as well as in the negative control line EC, even when higher amounts $(10 \mu \mathrm{g})$ of total RNA were loaded (Figure S1c).

The level of siRNA accumulation derived from the transgene transcript was analyzed by Northern-blot hybridization using the same probe as above. In lines containing the transgene, a positive signal with a size of approximately $20 \mathrm{nt}$ was detected only in line 72E; no signals were visible for lines 51-6, 82a, and EC (Figure S1d).

\subsection{DCL2/4-Knockdown Transgenic Tomato Line 72E Developed Severe Disease Symptoms upon PSTVd Infection}

Line 72E contains a single copy of the transgene and expresses high levels of transgene transcript and their corresponding siRNA. Therefore, changes in the appearance of line 72E plants in response to PSTVd infection were compared to those seen in other lines.

Ten plants each from lines EC and 51-6 showed very mild leaf curl four weeks after PSTVd inoculation and continued to grow, showing only slight growth retardation compared to the uninoculated healthy controls. In contrast, all ten plants of line 72E started to show curling on the newly expanding apical leaves two weeks post inoculation (wpi); this curling then became more severe, chlorosis appeared on the expanded leaves, and the mid-veins and/or petioles became necrotic around 3 wpi. The symptoms rapidly worsened between $3-4$ wpi (Figure $2 a$, b and Figure S2). Nine plants of line 82a (even though the expression of neither transgene transcript nor siRNA was evident) showed mild leaf curl and chlorosis at 3 wpi (Figure S2), symptoms that were milder than those on line 72E. Continued observation of infected line 72E plants revealed that growth almost stopped around $4 \mathrm{wpi}$, the severe necrosis first observed in the lower leaves became systemic, and, finally, the plants died three to four months post inoculation (Figure 2b). The infection assays were performed three-times under the same conditions and the results were in agreement with those above.

(a) EC / PSTVd

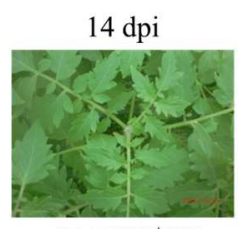

no symptom

(b) $72 \mathrm{E} / \mathrm{PSTVd}$

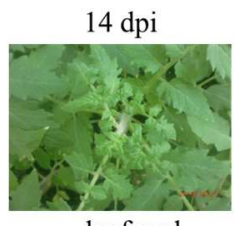

leaf curl
$21 \mathrm{dpi}$

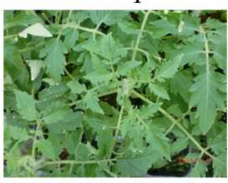

mild leaf curl

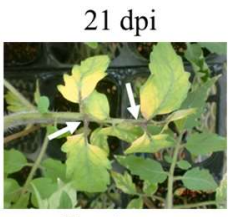

yellowing, stem necrosis

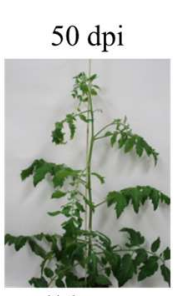

mild stunt

$28 \mathrm{dpi}$

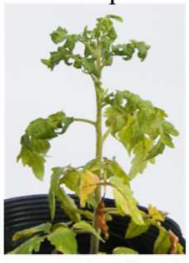

stunt, leaf curl, yellowing, necrosis

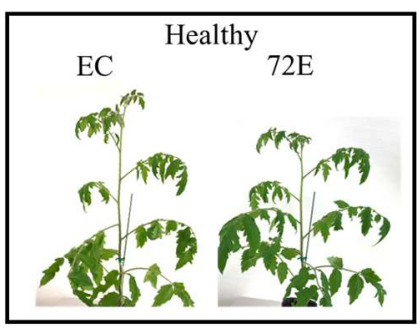

$118 \mathrm{dpi} \quad 137 \mathrm{dpi}$

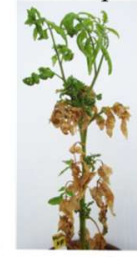

systemic necrosis

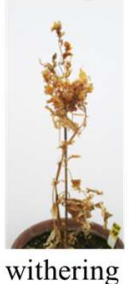

withering

Figure 2. Lethal necrotic symptoms associated with potato spindle tuber viroid (PSTVd) infection in the DCL2/4i-72E 'Moneymaker' tomato line. The upper row (a) indicates line EC infected with PSTVd. Plants showed mild leaf curling $\sim 21 \mathrm{dpi}$ and mild stunting at $50 \mathrm{dpi}$. The lower row (b) indicates line 72E infected with PSTVd. Infected plants started to show yellowing and stem necrosis around 3-4 weeks after inoculation, then showed severe systemic necrosis around 2-3 months post inoculation, and finally stopped growing and died. Plants in the box are healthy lines 72E and EC ( 50 dpi). Three replicates of plants showed similar symptoms. Photos were taken on the days indicated above the pictures. 


\subsection{High Levels of PSTVd Accumulated in Line 72E in the Early Stages and PSTVd Differentially Accumulated in Transgenic Lines}

Total RNA extracted from the upper leaves of nine to ten individual tomato plants from each line at 2,3, and 4 wpi was used to monitor the levels of PSTVd accumulation by Northern-blot hybridization using a DIG-labeled PSTVd-cRNA probe. PSTVd was detected in almost every inoculated plant, even at 2 wpi (10/10 plants infected in line EC, 8/10 in line 51-6, 10/10 in line 72E, and 9/9 in line 82a). One or two weeks later, all plants were infected (Figure S3).

The intensity of the PSTVd-positive signal was visibly higher in line 72E compared to the other lines, especially at 2 and 3 wpi (Figure S3). Therefore, the intensities of each signal were quantified using the Quantity One software (BioRad), normalized by comparison with the signal intensities obtained with ethidium bromide staining, and then averaged per line per week. Finally, relative intensities were calculated by defining the average value of line EC at 2 wpi as 1.0. These calculations confirmed that relative accumulation levels were actually higher in line 72E early in the infection: From high to low at 2 wpi, lines 72E ( 2.1), EC (1.0), 82a ( 0.75), and 51-6 ( 0.7); at 3 wpi, lines 72E ( 2.8), 82a ( 2.1), EC ( 1.9), and 51-6 ( 1.45) (Figure 3). Furthermore, although PSTVd concentrations in line $72 \mathrm{E}$ were twice as high as those in the other lines at 2 to $3 \mathrm{wpi}$, progeny levels were approximately the same later in the infection (lines 82a ( 3.3), $72 \mathrm{E}(\sim 3.2)$, EC ( 3.2), and 51-6 ( 3.0) at 4 wpi). Relative accumulation levels were somewhat lower in lines 82a and 51-6 at 2 wpi than that in line EC, but further examination is necessary to see whether this has important meaning.

The complete nucleotide sequences of PSTVd progenies propagated in lines 72E and EC were examined by using cDNA clone-sequencing (10 each of cDNA clones) and by analysis using the deep sequencing data of PSTVd-sRNAs, as described by Suzuki et al. [68], and found that they were virtually identical to the original sequence infected, although some minor singleton mutations, probably raised by replication error or misincorporation during PCR, were detected.

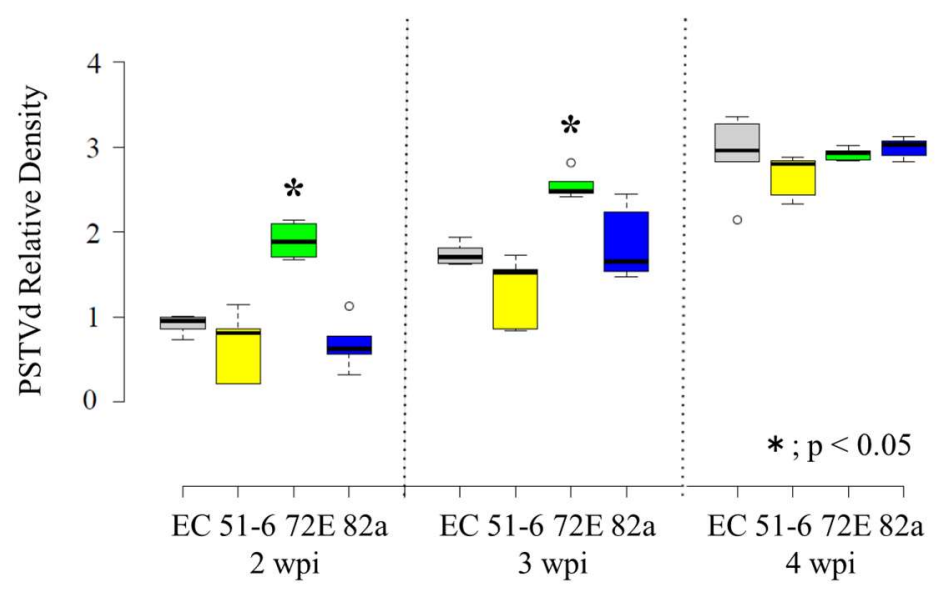

Figure 3. The relative density of PSTVd in three lines of the DCL2/4i Moneymaker tomato and the empty cassette control line at 2, 3, and 4 wpi. Five replicates of PSTVd-positive signals obtained by Northern-blot hybridization were quantified by ChemiDoc XRS, normalized using the gel image stained with ethidium bromide, and the averages were plotted on the graph. The thin vertical lines on the top indicate the error bar. The average value of the empty line at 2 wpi was adjusted as 1.0. The value in line 72E at 2 and 3 wpi with asterisks $\left(^{*}\right)$ were statistically significant at $5 \%$ level $(p<0.05)$. Boxplots were drawn in BoxplotR [69] using the Tukey whisker extent. Center lines show the medians; box limits indicate the 25th and 75th percentiles as determined by $\mathrm{R}$ software; whiskers extend to 1.5-times the interquartile range from the 25 th and 75 th percentiles, and outliers are represented by dots. $n=3$ sample points. 


\subsection{PSTVd Infection Activates DCLs}

The levels of SIDCLs (1, 2a, 3, and 4) transcripts before and after PSTVd infection in line 72E were analyzed by RT-qPCR (Figure 4). Before PSTVd infection, the levels of SIDCL2a and SIDCL4 transcripts in healthy line 72E plants were significantly lower $(p<0.05)$ than those in the healthy line EC plants. In contrast, levels of SIDCL1 transcripts were almost identical, and levels of SIDCL3 transcripts were slightly (but not significantly) lower in line 72E. This result, as expected, indicated that expression of the SIDCL2 $a$ and SIDCL4 genes had been down-regulated in line 72E by RNAi before PSTVd infection. In contrast, transcript levels of SIDCL1, 2a, 3, and 4 were all significantly up-regulated in line 72E after PSTVd infection. The increase in SIDCL1 was especially remarkable $(p<0.01)$. This was also true for line EC, indicating that transcription of SIDCL1-4 was activated by PSTVd infection but that changes were somewhat bigger in line 72E than in line EC.
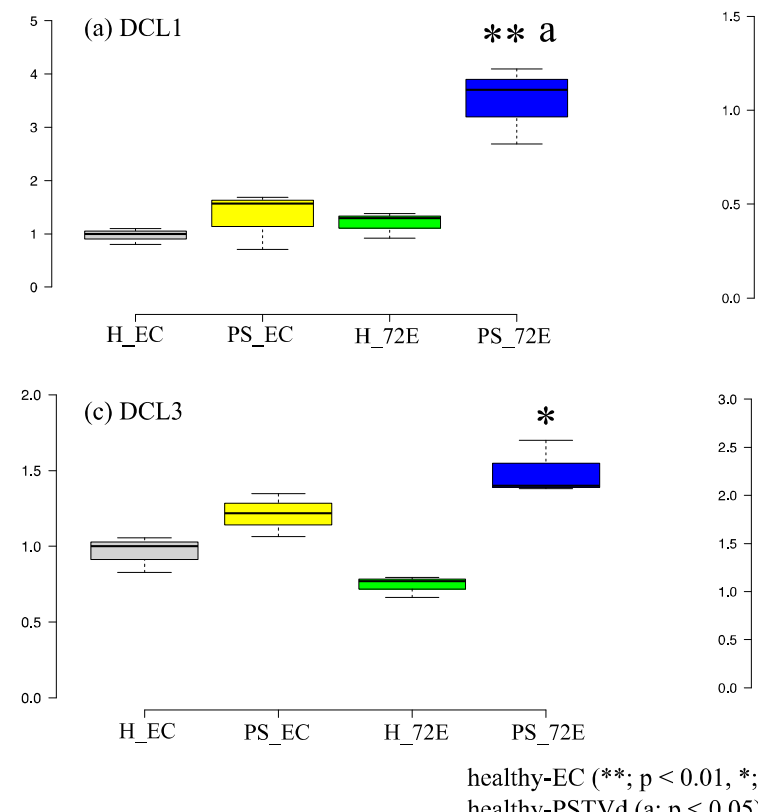

healthy-PSTVd $(\mathrm{a} ; \mathrm{p}<0.05)$
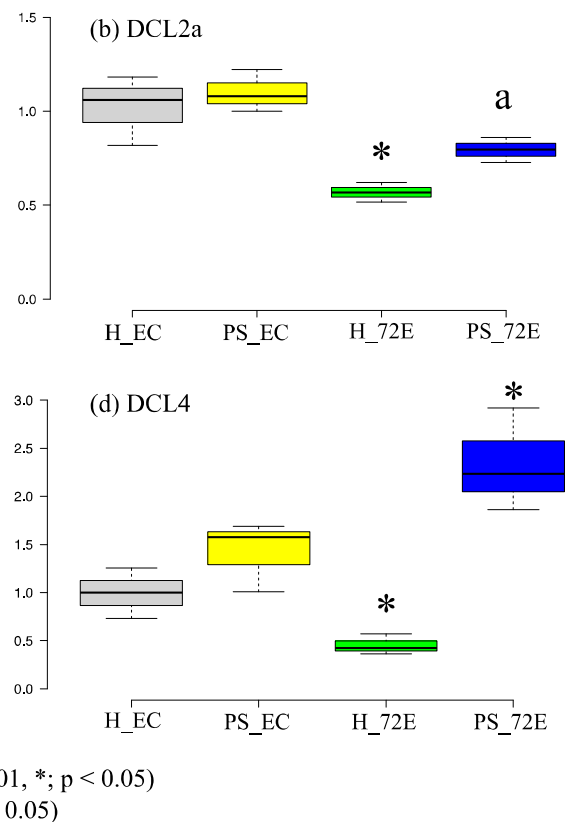

Figure 4. RT-qPCR analysis of endogenous SIDCL1, 2a, 3, and 4 mRNAs in lines 72E and EC with or without infection of potato spindle tuber viroid (PSTVd) using the leave at 3 wpi. Levels of SIDCL2a and 4 mRNAs in line 72E were significantly lower compared to those in the empty cassette before PSTVd infection, suggesting that endogenous SIDCL2a and 4 mRNAs were successfully down-regulated in line 72E (b,d). Levels of mRNAs of SIDCL1, 3 and 4 were significantly up-regulated in line 72E by PSTVd infection (a,c,d). Surprisingly, SIDCL2a was also up-regulated in line 72E compared to the healthy line, suggesting that the expression of tomato DCL genes are significantly activated by PSTVd infection (b). The assay was repeated twice, and each analysis consisted of three biological replicates collected from three plants per treatment. The values with the double asterisk $(* * p<0.01)$ and single asterisk $\left.{ }^{*} ; p<0.05\right)$ were statistically significant at $1 \%$ and $5 \%$ levels compared to healthy-EC. The values with "a" (a; $p<0.05)$ were statistically significant at the $5 \%$ level compared to PSTVd-EC.

Furthermore, since the nucleotide sequence of SIDCL2a used for the transgene was very similar to those of SIDCL2b (89\%), SIDCL2c (93\%), and SIDCL2d (90\%) (Figure 1), the expression levels of these SIDCL2s genes were also examined. As a result, the level of mRNA of SIDCL2d was significantly low in line $72 \mathrm{E}(\sim 60 \%$ of that of EC) compared to that in line EC before PSTVd infection, and up-regulated after infection but still $\sim 70 \%$ of that of line EC (Figure S4a). On the other hand, levels of mRNAs of SIDCL2b and SIDCL2c were considerably lower either in line EC and 72E before and after PSTVd infection (Figure $\mathrm{S} 4 \mathrm{~b}, \mathrm{c}$ ), suggesting that the expression of these genes was originally very low. 
3.5. Changes in PSTVd-Derived sRNA in PSTVd-72E; PSTVd-sRNA of 21 and 22 t Species Decreased and 24 nt Species Increased in the Transgenic Line 72E in Response to the Knockdown of DCL2 and DCL4

\subsubsection{Northern-Blot Hybridization Analysis}

In order to analyze the accumulation of PSTVd-derived sRNA (PSTVd-sRNA), groups of RNA extracts from nine to ten plants collected at weekly intervals were combined, aliquots $(\sim 10 \mu \mathrm{g})$ were fractionated by electrophoresis in an $8 \mathrm{M}$-urea $12 \%$ PAGE, transferred to nylon membrane, and hybridized with a DIG-labeled PSTVd-cRNA probe. Results revealed detectable levels of PSTVd-sRNA in lines EC and 72E even at 2 wpi; their size distributions were quite different, however. In the negative control line EC, the predominant species was $22 \mathrm{nt}$. In line 72E the major peak was two nucleotides longer (24-nt). This difference could be seen more clearly in the 3- and 4-week samples. Here, lines EC, 51-6, and 82a all accumulated abundant 22 and/or $21 \mathrm{nt}$ species and a small amount of $24 \mathrm{nt}$ species. Line 72E, in contrast, accumulated higher amounts of $24 \mathrm{nt}$ species and trace levels of $21 \mathrm{nt}$ species; the $22 \mathrm{nt}$ species was virtually invisible in this sample (Figure 5). Note also that accumulation of PSTVd-sRNA increased in parallel with an increase in PSTVd genome RNA accumulation over $2-4$ wpi.

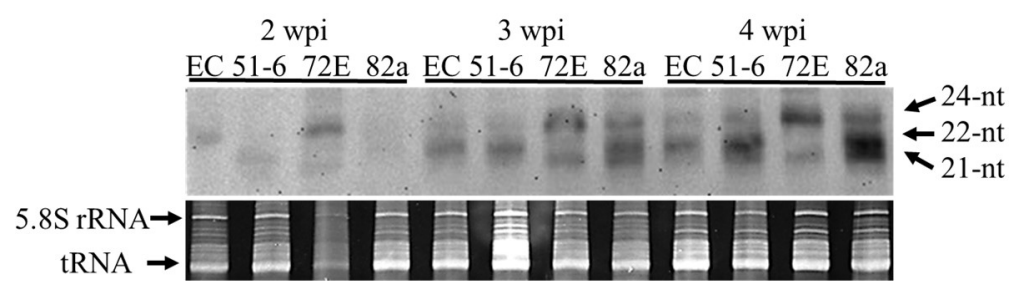

Figure 5. Time course analysis of PSTVd-sRNA accumulating in PSTVd-infected DCL2/4i-transgenic tomato lines. Total RNAs $(\sim 10 \mu \mathrm{g})$ extracted from three transgenic lines inoculated with PSTVd and line EC at 2, 3, and 4 wpi were separated in 8M-urea 12\% PAGE, transferred to nylon membrane, and analyzed by RNA gel-blot hybridization analysis using a DIG-PSTVd-cRNA probe. The upper panel shows the hybridization signal and the lower panel shows the loading control stained with ethidium bromide. All the lines except for 72E showed a dense hybridization signal at the position $22 \mathrm{nt}$ and faint signals at 21 and $24 \mathrm{nt}$. In contrast, line 72E showed a dense signal at $24 \mathrm{nt}$ and a faint signal at $21 \mathrm{nt}$. The signal at $22 \mathrm{nt}$ was invisible.

The difference in the size distribution of PSTVd-sRNAs observed in line 72E is consistent with the suppression of SIDCL2s and SIDCL4 expression by RNAi in the line. That is, the decrease in $21 \mathrm{nt}$ species can be explained by down-regulation of SIDCL4 which is responsible for producing $21 \mathrm{nt}$ sRNAs. Similarly, the decrease in $22 \mathrm{nt}$ species is consistent with down-regulation of SIDCL2s responsible for the production of $22 \mathrm{nt}$ species. It should be noted here that the observed decrease in $21 \mathrm{nt}$ species was not as pronounced as that in $22 \mathrm{nt}$ species.

\subsubsection{Deep Sequencing Analysis}

It is generally accepted that vd-sRNA processed by multiple DCLs activities after induction of RNA silencing may play a major role in viroid pathogenesis or symptom expression. Thus, we carried out deep sequencing analysis of sRNAs prepared from PSTVd-72E and compared the changes in PSTVd-sRNA, host miRNAs, and the other sRNAs with those observed in PSTVd-EC. The sRNA data sets obtained by Illumina Hiseq small RNA analysis contained a total 23,604,108 reads ranging in size from 15-45 nt in PSTVd-72E sampled at 3 wpi and 23,864,986 reads in the comparable sample from PSTVd-EC.

Allowing a maximum of $1 \mathrm{nt}$ mismatch, PSTVd-sRNA sequences accounted for 678,643 reads in PSTVd-72E and 554,261 reads in PSTVd-EC samples. PSTVd-sRNAs in PSTVd-72E comprised 383,947 reads $(69 \%)$ from plus-strand and 170,091 reads (31\%) from the minus-strand., i.e., sRNAs 
derived from the plus-strand were slightly more than twice as abundant as those from the minus-strand (Figure S5). This ratio was very similar in line EC; i.e., 318,585 reads (63\%) to 188,092 reads (37\%).

In contrast, and as expected from the data obtained by RNA gel-blot hybridization, the size distributions of PSTVd-sRNAs in these two lines were quite different. In line EC, the most abundant size class was $22 \mathrm{nt}(50 \%)$, followed by $21 \mathrm{nt}(36 \%), 24 \mathrm{nt}(5 \%)$, and $23 \mathrm{nt}(5 \%)$, a result which corresponded to our previous data obtained from PSTVd-infected 'Rutgers' tomato [9,70]. In PSTVd-72E, however, the most abundant size class was $24 \mathrm{nt}$ (53\%), followed by $21 \mathrm{nt}(23 \%), 17 \mathrm{nt}(18 \%), 23 \mathrm{nt}(4 \%)$, and $22 \mathrm{nt}(3 \%$ ) (Figure 6a,b). These results were quite consistent with the data obtained by RNA-gel blot assay described above. That is, by knocking down DCL2s and DCL4 expression using an RNAi strategy, the number of PSTVd-sRNA reads containing $22 \mathrm{nt}$ in PSTVd-72E dropped sharply to levels about one-twentieth of those seen in line EC plants (i.e., from 253,425 reads in PSTVd-EC to 14,257 in PSTVd-72E), but the number in the 24 nt class increased approximately 10 -fold (i.e., from 27,255 reads in PSTVd-EC to 295,542 reads in PSTVd-72E). The number in the $21 \mathrm{nt}$ class also decreased in PSTVd-72E, but this decline was much smaller than in the $22 \mathrm{nt}$ class, even though expression of DCL4, as well as DCL2s, was knocked down, suggesting that DCL1, in addition to DCL4, plays an important role in the production of $21 \mathrm{nt}$ PSTVd-sRNA (see Discussion session).

(a) EC-PSTVd

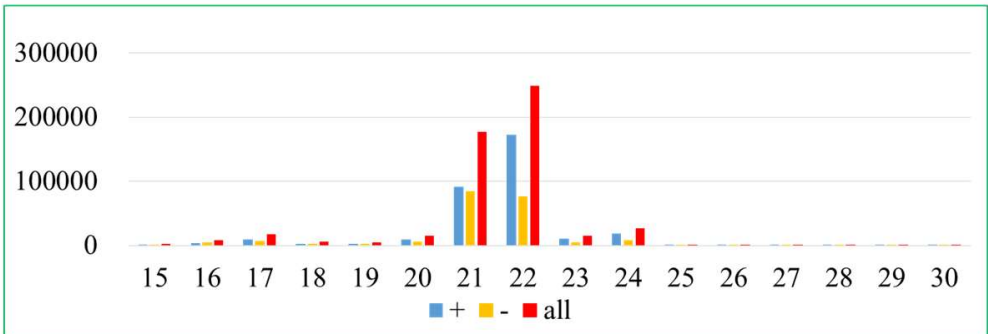

(b) 72E-PSTVd

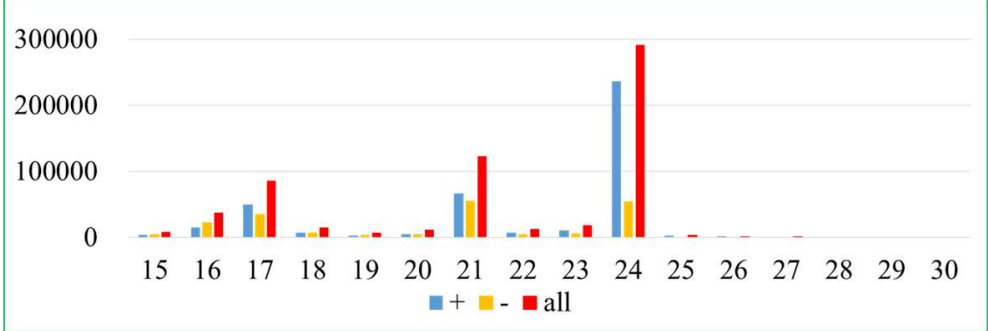

(c) EC-PSTVd

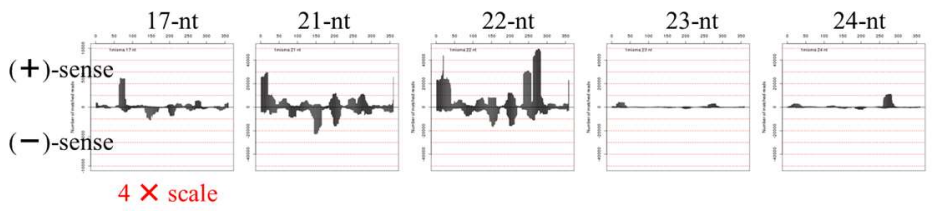

(d) 72E-PSTVd

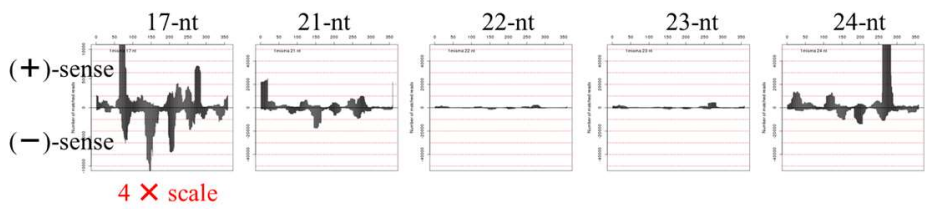

Figure 6. Size distribution and positive (+)/negative (-) ratio of PSTVd-sRNAs of the size 15-30 nt accumulated in lines (a) EC and (b) 72E. Panels (c) and (d) compare the PSTVd-sRNA hotspot patterns for the $17 \mathrm{nt}, 21 \mathrm{nt}, 22 \mathrm{nt}, 23 \mathrm{nt}$, and $24 \mathrm{nt}$ species in lines EC (c) and 72E (d). 
Interestingly, molecules in the $17 \mathrm{nt}$ class accounted for $18 \%$ of the total PSTVd-sRNA reads and were ranked the third most abundant class in PSTVd-72E. At present, it is not clear why the $17 \mathrm{nt}$ class increased so extensively in line 72E, and the possible function of the $17 \mathrm{nt}$ class has yet to be determined. It should be noted here that the majority of these molecules originate from the upper portion of the pathogenicity region; furthermore, the most abundant member of this class, which accounted for 17,606 reads ( 19.2\%) corresponds to nucleotides 63-79 in the PSTVd genome (5'-AGGCGGCUCGGAGGAGC-3').

Although the size distributions of PSTVd-sRNA were quite different for PSTVd-72E and PSTVd-EC, the hotspot patterns were virtually identical. This was most evident for the $21 \mathrm{nt}$ species in which the total numbers of reads for the two lines were not significantly different (Figure $6 c, d$ ). Interestingly, this was also the case for the $22 \mathrm{nt}$ and $24 \mathrm{nt}$ species where the total numbers of PSTVd-sRNA reads were significantly different; i.e., it was clear that the hotspot patterns of PSTVd-sRNAs in PSTVd-72E and PSTVd-EC were virtually identical when the scales of vertical axis were normalized.

Note also that the hotspot patterns seen in this analysis were very similar to those from PSTVd-infected 'Rutgers' tomato presented in our earlier report [11], indicating a high degree of reproducibility among multiple deep sequencing analyses (Figure S6). The fact that the hotspot pattern of PSTVd-sRNA remained constant even when the size distribution changed substantially suggested that even a significant change in the hierarchical order of DCL function caused by RNAi-mediated down-regulation of DCL2s and DCL4 expression was not sufficient to change the potential recognition sites and cleavage activities of the individual DCLs.

3.6. Changes in Host sRNAs and miRNA Expression Levels in PSTVd-72E and-EC; PSTVd Infection Up-Regulated miR398 and miR398a-3p

In PSTVd-72E, expression levels of all four DCLs were altered, and, as a result, the size distribution of PSTVd-sRNA changed extensively. Also, because the overall response to PSTVd infection in line 72E changed from tolerance to high sensitivity, relative levels of miRNAs and other host-derived sRNA species in this line were compared with those in PSTVd-EC plants. As described above, these comparisons were made using $21 \mathrm{nt}$ species in which the total number of reads did not change so much between lines 72E and EC. After the normalization to the ratio per million reads, comparisons of all sRNAs present at levels more than 50 reads per million revealed that 12 species of miRNAs were upor down-regulated by more than three-times in PSTVd-72E. The data presented in Table 1 reveal that nine species of miRNAs were up-regulated, whereas three species were down-regulated. In particular, miR398 and miR398a-3p showed unusually high expression levels in PSTVd-72E, where the number of reads per million increased from 311 to 2080 and from 1922 to 16,676, respectively. As described below, these miRNAs are known to target the mRNA of superoxide dismutase which removes harmful ROS from the cell.

As shown in Table 1, several sRNAs of host origin, other than miRNA species, were also detected. Some of these greatly fluctuated in the number of reads in PSTVd-72E, but the others did not fluctuate (Table 1). The top five (i.e., miR166b, 25S rRNA (LOC108175346), miR159a precursor RNA, miR166c, and miR396b) were almost the same in order; i.e., a difference was only seen in the order of the 4 th and 5th places. Interestingly, 12 of the top 50 sRNAs in PSTVd-72E were those derived from SIDCL2s (9 species with 7596-1775 reads/million) and SIDCL4 (3 species with 6845-2019 reads/million); however, they were approximately zero in PSTVd-EC. Therefore, it was confirmed that RNAi-mediated digestion of transgene-derived and/or endogenous transcripts of SIDCL2a and SIDCL4 genes actually took place in line 72E plants. Of particular interest was that not only siRNAs of SIDCL2a but also a large number of those that could have been derived from SIDCL2c and SIDCL2d were also detected in PSTVd-72E (Table 1). That is, as described above, since a highly similar-region of SIDCL2s was used for the construction of a transgene, it was suggested that inhibitory action was exerted not only on SIDCL2 $a$ but also on the other mRNAs of SIDCL2s; i.e., SIDCL2c and SIDCL2d at least. As described, 
cross-inhibition of expression of the other SIDCLs by the SIDCL2a and $2 b$ transgene was confirmed in SIDCL2d by RT-qPCR analysis.

Table 1. Changes in tomato sRNA levels in lines potato spindle tuber viroid (PSTVd) -72E and -EC.

\begin{tabular}{|c|c|c|c|c|}
\hline \multirow{2}{*}{ Name Small RNA } & \multicolumn{2}{|c|}{ Empty Casette } & \multicolumn{2}{|c|}{$72 \mathrm{E}$} \\
\hline & Rank & Reads*1 & Rank & Reads * 1 \\
\hline \multicolumn{5}{|l|}{ Top 5} \\
\hline miR166d-3p & 1 & 176,745 & 1 & 190,257 \\
\hline 25S rRNA (LOC108175346) & 2 & 89,566 & 2 & 133,774 \\
\hline $\operatorname{miR} 159 a$ & 3 & 31,728 & 3 & 45,000 \\
\hline $\operatorname{miR} 166 c$ & 4 & 30,583 & 5 & 21,196 \\
\hline miR396b & 5 & 26,599 & 4 & 27,205 \\
\hline \multicolumn{5}{|l|}{ micro RNA } \\
\hline miR398a-3p * & 41 & 1922 & 8 & 16,676 \\
\hline $\operatorname{miR} 398^{*}$ & 263 & 311 & 39 & 2035 \\
\hline $\operatorname{miR} 166$ & 31 & 2260 & 30 & 8450 \\
\hline miR171e & 1578 & 33 & 374 & 184 \\
\hline miR393-3p & 1098 & 52 & 259 & 275 \\
\hline $\operatorname{miR} 397-5 p$ & 437 & 176 & 101 & 769 \\
\hline miR408b-3p & 151 & 528 & 40 & 1996 \\
\hline miR4376-5p & 54 & 1417 & 18 & 4375 \\
\hline miR1919-3p & 1037 & 57 & 411 & 159 \\
\hline miR166b & 13 & 7386 & 30 & 2500 \\
\hline miR399i-3p & 401 & 152 & 1432 & 29 \\
\hline miR477-5p & 878 & 71 & 2274 & 15 \\
\hline \multicolumn{5}{|l|}{ ribosomal RNA } \\
\hline 25S rRNA (LOC108175346) & 10 & 8109 & 721 & 76 \\
\hline 25S rRNA (LOC108175346) & 17 & 3893 & 1355 & 32 \\
\hline 25S rRNA (LOC108175346) & 20 & 2970 & 1224 & 37 \\
\hline 25S rRNA (LOC108175346) & 27 & 2623 & 494 & 130 \\
\hline 25S rRNA (LOC108175346) & 28 & 2595 & 811 & 68 \\
\hline 25S rRNA (LOC108175346) & 45 & 1739 & 15,448 & 2 \\
\hline \multicolumn{5}{|l|}{ Dicer-related } \\
\hline DCL2a or $2 d$ & 11,234 & 2 & 14 & 7596 \\
\hline DCL4 & 48,061 & 1 & 15 & 6696 \\
\hline DCL2c & - & 0 & 16 & 5781 \\
\hline DCL2a or $2 \mathrm{c}$ & - & 0 & 19 & 4014 \\
\hline DCL2a or $2 \mathrm{c}$ & - & 0 & 24 & 3173 \\
\hline DCL2c & - & 0 & 25 & 3145 \\
\hline DCL4 & - & 0 & 32 & 2448 \\
\hline DCL2a & - & 0 & 33 & 2401 \\
\hline DCL2a & - & 0 & 34 & 2213 \\
\hline DCL4 & - & 0 & 35 & 2109 \\
\hline DCL2a or $2 \mathrm{c}$ & - & 0 & 42 & 1919 \\
\hline DCL2a & - & 0 & 45 & 1775 \\
\hline \multicolumn{5}{|l|}{ PHAS } \\
\hline Sly-PHAS16 precursor siRNA & 19 & 3158 & 2426 & 14 \\
\hline Sly-PHAS04 & 49 & 1545 & 54,902 & 1 \\
\hline \multicolumn{5}{|l|}{ others } \\
\hline uncharacterized ncRNA (LOC101245085) & 15 & 4564 & - & 0 \\
\hline DNA-directed RNA polymerase III subunit 1 & 21 & 2968 & 177 & 414 \\
\hline Solanum lycopersicum chromosome 1 & 151 & 451 & 40 & 1996 \\
\hline probable indole-3-pyruvate monooxygenase & 44 & 1749 & 1520 & 22 \\
\hline
\end{tabular}

* This table shows a list of tomato sRNAs with more than 50 reads per million which changed more than three-times between PSTVd-EC and PSTVd-72E. Those up-regulated in PSTVd-72E were shown in pink, while down-regulated ones were in blue. MiR398 and miR398a-3p were up-regulated $770-868 \%$ in the $21 \mathrm{nt}$ sRNA population from PSTVd-72E compared to those from PSTVd-EC. MiR398 and miR398a-3p have been reported to target Cu/Zn-SODs (CSD1, CSD2, and CCS1) in Arabidopsis spp. and possibly in the tomato. Levels of miR166b in line PSTVd-72E were only half of those found in PSTVd-EC. 
In addition, it should be noted here that five species of $21 \mathrm{nt}$ sRNAs derived from $25 \mathrm{~S}$ rRNA decreased in number extensively from 8,109-1,739 to 130-37, Sly-PHAS16 precursor siRNA decreased from 3,158 to 14, and Sly-PHAS04 precursor siRNA decreased from 1545 to 1.

3.7. Northern-Blot Hybridization of miR398a-3p in Healthy and PSTVd-Infected Lines 72E and EC; PSTVd Infection Up-Regulated miR398a-3p

Since the greatest increase was seen in miR398a-3p by deep sequencing analysis, the expression levels of miR398a-3p after PSTVd infection were also examined by Northern-blot hybridization. Aliquots $(10 \mu \mathrm{g})$ of total RNA, extracted from healthy and PSTVd-infected lines 72E and EC were fractionated by $8 \mathrm{M}$-urea $12 \%$ PAGE, transferred to a nylon membrane, and hybridized with a DIG-labeled cRNA probe for miR398a-3p. As shown in Figure 6, miR398a-3p was not detectable in healthy plants from either line, indicating that expression levels of miR398a-3p were very low. In contrast, in PSTVd-infected plants, miR398a-3p reached detectable levels at 3 wpi (Figure 7a, arrow), indicating that PSTVd infection stimulates expression of miR398a-3p. In agreement with the deep sequencing data, the level of miR398a-3p in PSTVd-72E was approximately five times higher than that in the comparable PSTVd-EC plants, reconfirming that RNAi-mediated down-regulation of DCL2s and DCL4 results in enhanced expression. This analysis was repeated twice and yielded similar results.

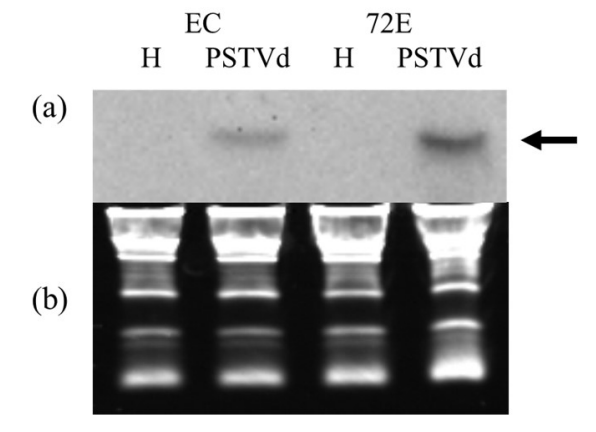

Figure 7. Northern-blot hybridization of miR398a-3p. Aliquots $(10 \mu \mathrm{g})$ of total RNA, isolated at 3 wpi, were fractionated by electrophoresis in $8 \mathrm{M}$-urea $12 \%$ PAGE, transferred to nylon membrane, and hybridized with a DIG-labeled cRNA probe for miR398a-3p. (a) Band signals were visualized with ChemiDoc XAR (BioRad) and quantified with Quantity One software (Bio-Rad). MiR398a-3p was detectable only after PSTVd infection (arrow), and signal intensities were approximately five-times higher in line 72E as compared to a control line EC. (b) The loading control stained with ethidium bromide. This analysis was repeated twice.

\subsection{Expression of Tomato SODs in Healthy and PSTVd-Infected Lines 72E and EC}

In line 72E, infection with PSTVd caused severe systemic necrosis and induced unusually high levels of expression of miR398 and miR398a-3p. MiR398 is a miRNA that negatively regulates SOD, which normally scavenges harmful ROS. When Arabidopsis thaliana is exposed to oxidative stress arising from biotic or abiotic factors, miR398 expression is down-regulated at the level of transcription, and as a result, the post-transcriptional accumulation of $\mathrm{Cu} / \mathrm{Zn}-\mathrm{SOD} 1$ and $\mathrm{Cu} / \mathrm{Zn}-\mathrm{SOD} 2 \mathrm{mRNAs}$ is up-regulated, leading to the scavenging of ROS. This is an important regulatory function that enables plants to tolerate oxidative stresses [71]. Therefore, in order to investigate what is happening between these stress-responsive miRNAs and tomato SOD gene expression in the PSTVd-infected line 72E, the target sequences of tomato miR398 and miR398a-3p detected in this experiment were searched for in the tomato unigene database using psRNATarget software (URL; http://plantgrn.noble.org/psRNATarget/). As a result, the target sequences of miR398 were found in the gene sequences of cytosolic $\mathrm{Cu} / \mathrm{Zn}-\mathrm{SOD} 1$ (accession number SGN-U581590) and the copper chaperon for SOD, namely CCS1 (accession number SGN-U577152) (Figure S7). In addition, the target sequence of miR398a-3p was found in the gene sequence of chloroplast-localized $\mathrm{Cu} / \mathrm{Zn}-\mathrm{SOD} 2$ (Figure S7). Recently, Feng et al. [66] identified nine 
SOD genes (SlSOD1 to SISOD9) in tomato plants, and reported that SISOD1, SlSOD2, SISOD3, and SISOD4 all have $\mathrm{Cu} / \mathrm{Zn}-S O D$ motifs, and that SISOD1 and SISOD2 are cytosolic whereas SISOD3 is chloroplast-localized. It is therefore considered that SISOD1 and SISOD2 belong to what are referred to as cytosolic $\mathrm{Cu} / \mathrm{Zn}-\mathrm{SOD} 1 \mathrm{~s}$, and SISOD3 belongs to chloroplast-localized $\mathrm{Cu} / \mathrm{Zn}-\mathrm{SOD} 2$. Using a BLAST search analysis, the target sequence of miR398 was confirmed in the gene sequence of SISOD1 and SISOD2, and the target sequence of miR398a-3p was confirmed in the gene sequence of SISOD3. In addition, SISOD4, which is reported to have $\mathrm{Cu} / \mathrm{Zn}$ and heavy-metal binding motifs [66] has a nucleotide sequence similar to the CCS1 sequence reported previously (accession number NM_001347085, AK319564) and has the target sequence of miR398. Based on these findings, correlations among expression levels of miR398a-3p, SISOD1, SISOD2, SISOD3, and SISOD4 were analyzed using RT-qPCR. MiR398a-3p was selected for analysis because it was approximately eight-times more abundant than miR398 (Table 1).

Three plants each from lines 72E and EC were infected with PSTVd. Leaf discs were harvested from leaves 5 and 6 (numbers from the bottom) at 4 wpi for RNA extraction, when symptoms of yellowing accompanied by vein necrosis started to develop in the leaves 5 and 6 of line 72E (Figure 8a). For comparison, the upper (leaves 7 and 8 ) and the lower (leaf 4) leaves showing no vein necrosis were also harvested and treated similarly. For the control, RNA samples were obtained in a similar way from three plants each of healthy 72E and EC lines. The assay was repeated twice, with each analysis consisting of three biological replicates collected from three plants per treatment.

Extremely high levels of miR398a-3p were specifically detected in leaf 6 of the PSTVd-72E plants showing vein necrosis (Figure $8 \mathrm{~b}$, arrow). In contrast, the mRNAs expression levels of SISOD2, S1SOD3, and S1SOD4 in the same leaves were significantly lower compared with those in the upper and the lower leaves in PSTVd-72E plants, as they were in the healthy-EC, PSTVd-EC, and healthy-72E plants (Figure $8 \mathrm{c}$, arrow). A clear negative correlation was therefore present between the abnormally higher levels of miR398a-3p and significantly lower levels of SISOD3 mRNA in leaf 6 showing vein necrosis in line PSTVd-72E. This suggests that negative regulation of SISOD3 at the post-transcriptional level did occur in the leaves, as a result of the high levels of miR398a-3p. It is interesting to note that, as expected from Northern-blot analysis, elevated levels of miR398a-3p were observed in PSTVd-EC plants in leaves 4- 6, and that the expression levels of some SISODs, mRNAs (e.g., SISOD1 in leaf 6, SISOD3 in leaves 4-6, SISOD4 in leaf 6) were down-regulated to some extent (Figure 8b,c), however, these differences were much less pronounced compared with those in PSTVd-72E.

The levels of SISOD1, SISOD2, and SISOD4 mRNAs were also significantly decreased in leaf 6 of PSTVd-72E (Figure 8c, arrow) which showed necrosis. We have not yet fully explored this finding, but it is highly probable that the down-regulation of these SISODs was caused by the up-regulation of miR398, the negative regulator of these genes, because the up-regulation of miR398 in PSTVd-72E was already supported by the findings of our deep sequencing analysis of small RNAs (Table 1), and our preliminary RT-qPCR analysis indicated a high level of miRNA398 in leaf 6 of PSTVd-72E. It is necessary to further analyze the expression levels of miR398 in these leaves to clarify whether the high level of miR398 expression and down-regulation of SISOD1, SISOD2, and SISOD4 mRNAs are also involved in the onset of necrosis symptoms observed in line PSTVd-72E. It should be noted here that, although we have not yet identified the mechanism, the expression of SISODs, especially SISOD3, was somewhat higher in leaves 5 and 6 in 72E, even without PSTVd infection. 
(a) Symptoms on leaf 6
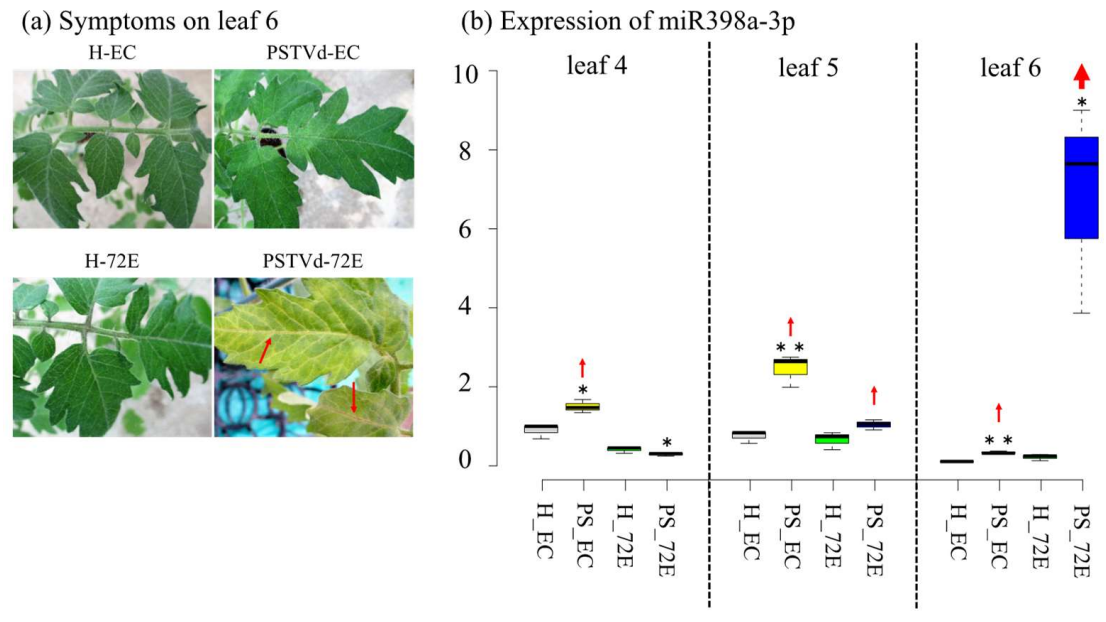

(c) Expression of SISODs
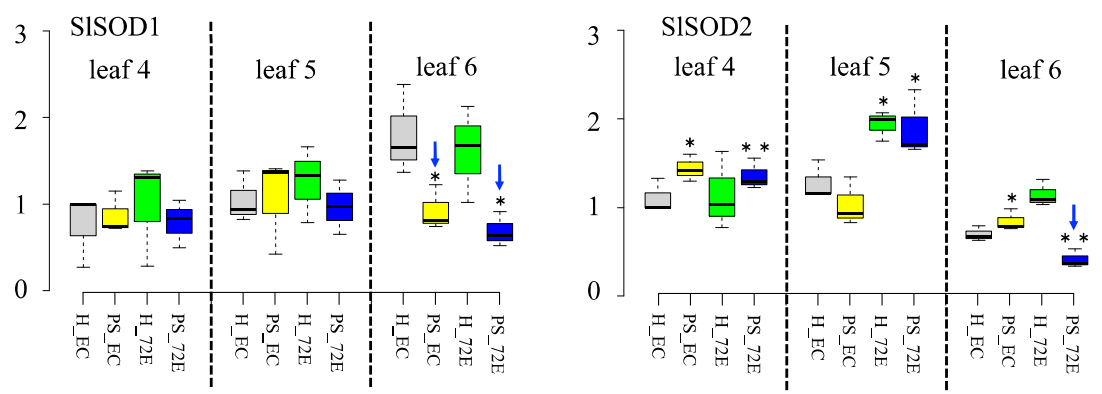

SISOD3

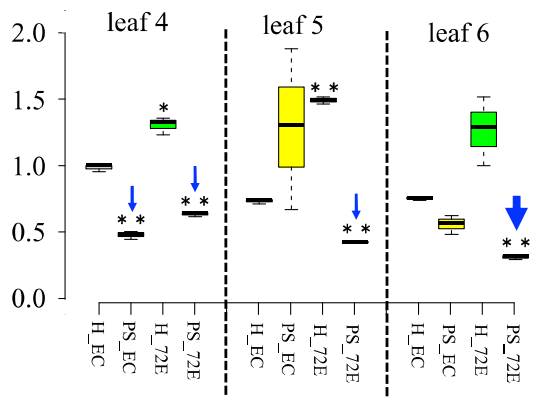

SISOD4

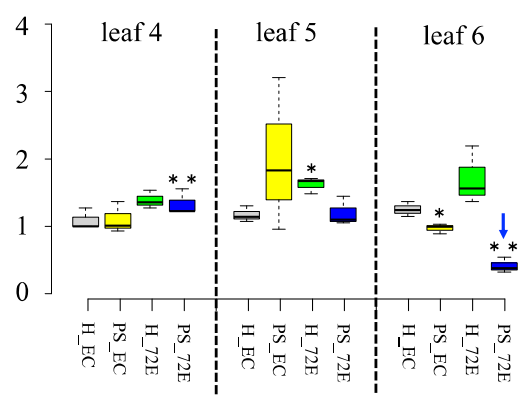

Figure 8. Analysis of miR398a-3p and tomato SODs expression levels in healthy leaves and PSTVd-infected leaves with or without showing necrosis. Panel (a): Three plants each of tomato lines 72E and EC were infected with PSTVd. At 4 wpi, only PSTVd-72E (PS_72E) started to show yellowing accompanied with vein necrosis (arrows) on leaves 5 and 6 (numbers from the bottom). Panel (b): RT-qPCR analysis of miR398a-3p expression revealed that levels of miR398a-3p were unusually high in leaf 6 of PS_72E, which showed necrosis (thick red arrow). Relatively high levels of expression were also found in leaves 4 and 5 in PSTVd-EC (PS_EC) and in leaf 5 in PS_72E (thin red arrow), but the levels were approximately four to five times lower than those in leaf 6 of PS_72E. Samples were collected at 4 wpi. The assay was repeated twice, and each analysis consisted of three biological replicates collected from three plants per treatment. Panel (c): RT-qPCR analysis of the expression of four tomatoes $\mathrm{Cu} / \mathrm{Zn}-\mathrm{SOD}$ (i.e., SISOD1, SISOD2, SISOD3, and SISOD4) in the same samples revealed that, in response to the highest level of miR398a-3p, SISOD3 expression decreased most significantly in leaf 6 of PS_72E (thick blue arrow) compared with the healthy line EC (H_EC). SISOD3 expression levels were also significantly decreased in leaves 4 and 5 of PS_72E, and in leaf 4 of PS_EC. In addition, SISOD1, SISOD2, and SISOD4 expression levels were significantly lower in leaf 6 of PS_72E (thin blue arrow), which showed necrosis. SISOD3 expression was somewhat higher in leaves 5 and 6 in H_72E. The values with the double asterisk $\left.{ }^{* *} ; p<0.01\right)$ and single asterisk $\left({ }^{*} ; p<0.05\right)$ were statistically significant at $1 \%$ and $5 \%$ levels compared to healthy-EC. 


\subsection{ROS Production and Scavenging Activity in PSTVd-Infected Line 72E}

Using the same plants as described above, the activity of the ROS hydrogen peroxide was assayed in the healthy and PSTVd-infected 72E and EC lines during the period of 4-10 wpi. This is because PSTVd-72E plants had stopped growing and severe necrosis symptoms were underdeveloped. Leaves 5 and 6, which showed vein necrosis, and a mixture of upper leaves without necrosis (leaves 7 and 8) were selected for the analysis, because, as described above, PSTVd-72E plants started to show yellowing and vein necrosis in the leaves 5 and 6 at 4 wpi, but showed only leaf curling in leaf 7 and above. The highest activity was observed in leaves showing necrosis in PSTVd-72E plants. Interestingly, the activity was also high in the corresponding leaves of healthy-72E plants. Average hydrogen peroxide activity in the leaves showing necrosis in PSTVd-72E plants was ca. 15- and five-times higher than in healthy-72E and in healthy-EC or PSTVd-EC. A statistically significant difference $(p<0.01)$ was found between healthy-EC and healthy- and PSTVd-72E plants (Figure 9a; Table S2). In contrast, the activity was equally low in all samples of upper leaves without necrosis, indicating that lower leaves with necrosis of PSTVd-72E plants showed higher levels of hydrogen peroxide activity.

(a)

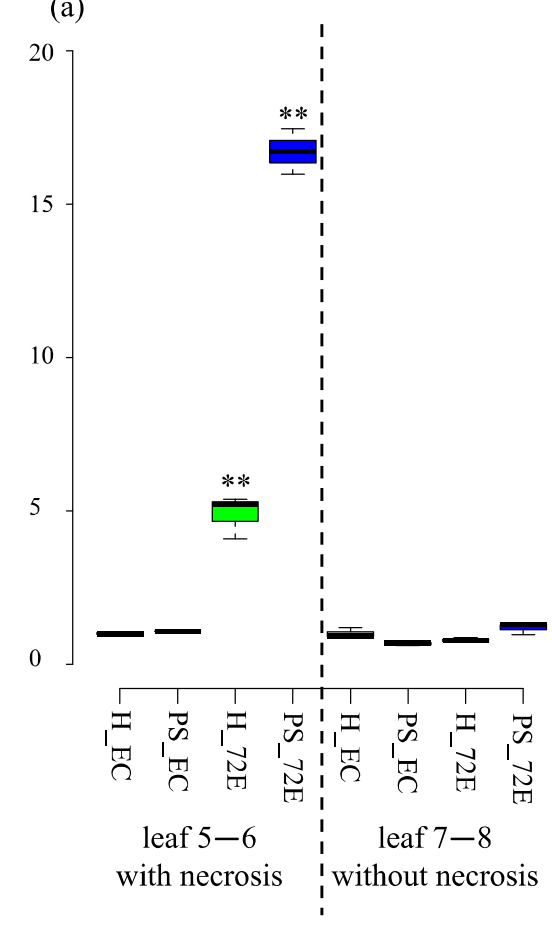

(b)

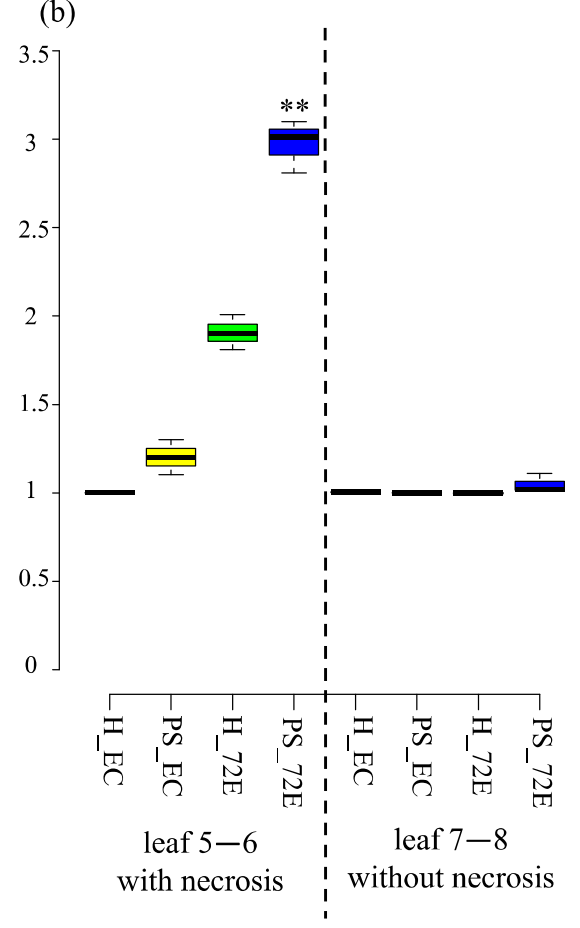

Figure 9. Relative ROS production (a) and relative ROS scavenging activity (b) in the leaves 5 and 6 (with necrosis) and leaves 7 and 8 (without necrosis). An unusually high level of ROS production and scavenging activity was found in leaves 5 and 6, showing necrosis in PSTVd-72E (PS_72E) compared with healthy-EC (H_EC) plants. A relatively high level of ROS production and scavenging activity was also detected in the leaves 5 and 6 of healthy-72E (H_72E) plants. Leaves of the same plants as described above were used for the analysis. The assay was repeated twice, and each analysis consisted of three biological replicates collected randomly from five plants per treatment. The center lines show the medians; the box limits indicate the 25 th and 75 th percentiles as determined using $\mathrm{R}$ software; the whiskers extend 1.5-times the interquartile range from the 25th and 75th percentiles; the dots represent outliers. The values with the double asterisk $(* * ;<0.01)$ was statistically significant at $1 \%$ level compared to healthy-EC.

Hydrogen peroxide scavenging activity was also assayed in the same leaves in both healthy and PSTVd-72E and -EC plants. Average hydrogen peroxide scavenging activity was $20 \%$ in healthy-EC, $27.5 \%$ in PSTVd-EC, 33.6\% in healthy-72E, and $44 \%$ in PSTVd-72E plants. A statistically significant 
difference $(p<0.01)$ was found between healthy-EC and PSTVd-72E plants (Figure 9b, Table S2), indicating that the leaves showing vein-necrosis in PSTVd-72E showed higher levels of hydrogen peroxide scavenging activity.

\section{Discussion}

In this experiment, by using RNAi-mediated matter, we produced a T3-generation of DCL2\&4-knockdown 'Moneymaker' tomato lines, transformed with an IR construct consisting of partial sequences of tomato homologs SIDCL2a, SIDCL2b, and DCL4. One of these lines, named line 72E, was shown to contain a single copy of the transgene and to express high levels of transgene transcript and related siRNAs.

Line 72E, when challenged by PSTVd inoculation, started to show apical leaf curl at approximately 2 wpi and exhibited systemic leaf chlorosis, accompanied by vein-necrosis at $3-4$ wpi. The plants subsequently stopped growing, developed more severe leaf necrosis (from lower to systemic), and finally died $4-5$ months after inoculation, suffering from lethal systemic necrosis. This was in contrast to line EC, which was used as a control. Since the 'Moneymaker' tomato is a tolerant cultivar to PSTVd infection [10,72], line EC showed very mild leaf curl and stunting during the observation period. Therefore, RNAi-mediated down-regulation of DCL2a and DCL4 expression changed the 'Moneymaker' tomato into being highly susceptible to PSTVd infection. Here we have to emphasize that in this experiment partial sequences of $D C L 2 a$ and $2 b$ were used to construct a transgene, and the sequence was so similar to the other DCL2s (i.e., $2 \mathrm{~b}, 2 \mathrm{c}$, and $2 \mathrm{~d}$ ) that they could be also down-regulated in some extent at the post-transcription level in the line 72E. Actually, as shown in Figure S5, the expression level of DCL2d decreased to $~ 60 \%$ of the control, therefore, the word "DCL2" in the following sentences includes the other DCL2s either.

In line with the severity of disease symptoms, PSTVd level was significantly higher (1.5-3.0 times) in line 72E than in the other lines in early infection (until 2 and 3 wpi) (Figure 3), indicating that DCL2a and DCL4 play an important role in protecting tomato plants from PSTVd-induced symptom expression by suppressing the initial replication and accumulation of PSTVd.

By the analysis of PSTVd-sRNA using RNA-gel blot assay, lines EC, 51-3 and 82a were found to have accumulated two major bands of the sizes 21 and $22 \mathrm{nt}$ and a weak band of $24 \mathrm{nt}$, whereas line 72E accumulated a dense $24 \mathrm{nt}$ band and faint $21 \mathrm{nt}$ band. The result was more evident in the data after deep sequencing: The number of PSTVd-sRNA reads of the sizes 21 and $22 \mathrm{nt}$ species in line $72 \mathrm{E}$ decreased to $\sim 66.7 \%$ and $\sim 5 \%$ of those in line EC, respectively, and the $24 \mathrm{nt}$ species in line $72 \mathrm{E}$ increased by $\sim 1100 \%$ that in line EC.

Considering the commonly accepted concept that DCL1, DCL2, DCL3, and DCL4 generate $21 \mathrm{nt}, 22 \mathrm{nt}, 24 \mathrm{nt}$, and $21 \mathrm{nt}$ sRNAs, respectively, the result clearly indicated that RNAi-mediated down-regulation of DCL2s and DCL4 resulted in a decrease of 21 and $22 \mathrm{nt}$ species; $24 \mathrm{nt}$ species, in contrast, increased significantly by relative superiority of DCL3 activity. The result is in line with the previous findings on the changes in the size distribution of virus- and viroid-derived sRNAs accumulated in $d c l 2$ and $d c l 4$ mutants and/or the knockdown lines [20,21,52,60,62]. The underlying mechanism behind this is a hierarchical interaction existing in the functions of DCLs in antiviral defense; i.e., DCL4 preferentially plays a major role in general. However, DCL2 is known to compensate for DCL4 function once DCL4 is destroyed or interfered [52,60,62]. Similarly, Katsarou et al. [21] reported, by using PSTVd-infected $d c l(\mathrm{~s})$ mutant lines of Nicotiana benthamiana, that the combined activity of DCL2 and DCL3 is important for anti-viroid defense. They presented a model that shows that DCL4 normally plays a major role in anti-viroid defense and suppresses the functions of DCL2 and DCL3. This was also the case in our experiment on the PSTVd-infected tomato hpDCL2/4i-72E line, in which the activity of DCL3 was significantly enhanced when expression of DCL2 and DCL4 was artificially suppressed.

Another dramatic increase found in $17 \mathrm{nt}$ species in the 72E line was particularly interesting because a majority of them were originated from the upper strand of the pathogenicity region. The 
biogenesis is unknown, but a similar mechanism, reported by Zhu et al. [73], may be included, in which bidirectional processing of pri-miRNAs with branched terminal loops by Arabidopsis spp. DCL1 results in the production of 16-17 nt species, because viroids can form branched terminal loop structures and DCL1 was active in the plants.

As described above, RNAi-mediated knockdown of SIDCL2s and SlDCL4 created a significant change in the size distribution of PSTVd-sRNAs. Nevertheless, the rate of decrease in 21 nt species (approximately 33\%) was apparently smaller than that in $22 \mathrm{nt}$ species (approximately 95\%). This big difference seems to contradict the data obtained by RT-qPCR on the expression of all four SlDCLs; namely, the rate of decrease in SIDCL2s and SIDCL4 expression in 72E line was approximately 50-60\% of the empty cassette, not so different from each other. Taking the result that the rate of decrease in the transcription level of SIDCL4 (producing $21 \mathrm{nt}$ species) was almost the same as that of SIDCL2a (produces $22 \mathrm{nt}$ species), and also the fact that DCL1 is also responsible for producing $21 \mathrm{nt}$ species, the results may indicate that DCL1 is actually involved in the processing of viroid RNA and contributes to the production of $21 \mathrm{nt}$ species of vd-sRNA, as suggested previously [74,75]. From this viewpoint, it is interesting to note that the expression level of SIDCL1 in line 72E significantly up-regulated after PSTVd infection (Figure 6a). Alternatively, another possible explanation will be a significantly elevated level of expression found in SIDCL4 after PSTVd infection (Figure 6d).

RT-qPCR analysis clearly indicated that PSTVd infection activated transcription level of SIDCL4 in line 72E. On the other hand, the activation of transcription by PSTVd infection was observed not only in SIDCL4 but also the other SIDCLs including SIDCL2s, indicating that expression of all the SIDCLs was activated by PSTVd infection. Since it was reported that the levels of DCL1, DCL2, and especially DCL4 transcripts were increased significantly in a wild type tomato (cv. 'Rutgers') by the infection of citrus exocortis viroid (CEVd), another member of the genus Pospiviroid [76], it may be a general phenomenon for viroids, at least those in the genus Pospiviroid.

An important point here is that the sensitivity to PSTVd infection largely changed in line 72E, even though all the DCLs expression levels seemed to increase or somewhat recover after PSTVd infection. The result seems to create a question that cannot be explained by the expression levels of individual DCLs. An appropriate balanced expression of all the DCLs may be important to express an optimum anti-viroid defense response. Further analysis on the activities of DCL enzymes, for example, is necessary to clarify this point.

Changes in miRNA reads in the sRNA deep sequencing data were analyzed in silico, and several miRNAs were found to have been up- or down-regulated in PSTVd-72E compared with PSTVd-EC. Among them, the increased numbers of miR398 (770\%) and miR398a-3p (868\%) in PSTVd-72E were extremely interesting. MiR398 and miR398a-3p are stress-responsive miRNAs, known to be expressed in response to various stresses, that inhibit the expression of cytosolic and chloroplastlocalized SODs [77,78] and copper chaperons for SOD (i.e., CCS1) [63], which scavenge harmful ROS. Northern-blot hybridization analysis clearly showed that miR398a-3p was detected exclusively from PSTVd-infected plants (both 72E and EC), with the intensity of the bands approximately five-times higher in PSTVd-72E compared with PSTVd-EC. These results, along with the observation that PSTVd-72E experienced severe systemic necrosis, strongly suggested that ROS are generated not only in PSTVd-72E but also in PSTVd-EC. The highest ROS production and scavenging activities were found in leaves showing necrosis in line PSTVd-72E, indicating that ROS were actively generated and then rapidly scavenging desperately in the plants. In contrast, even after PSTVd infection, the line EC did not show any visible necrotic symptoms or excessive ROS production. Therefore, the unusually higher levels of ROS production in PSTVd-72E seems to be a major reason for the development of severe necrotic reactions in these plants. More specifically, miR398 and 398a-3p must be down-regulated under normal conditions in order to enhance the function of SODs when ROS are produced following a viroid infection. However, as shown in Figure 8, the expression of miR398a-3p was particularly high in the leaves showing necrosis in PSTVd-72E (Figure 8b, leaf 6), and in response the expression of chloroplast-localized $\mathrm{Cu} / \mathrm{Zn}-\mathrm{SOD} 2 \mathrm{mRNA}$ (i.e., SISOD3 in tomatoes; Figure 8c, leaf 6 in SISOD3), which 
is negatively regulated by miR398a-3p, significantly decreased. This indicates that miR398a-3p, which must, in theory, be down-regulated, is conversely elevated in leaves showing necrosis in PSTVd-72E. Misregulation of miR398a-3p in PSTVd-72E causes dysfunction of SISOD3 localized in chloroplasts, resulting in the inability to regulate ROS scavenging, and subsequently leading to the development of severe systemic necrosis.

In conclusion, the results presented here clearly indicate that the tomato homologs of DCL2s and DCL4 provide strong but incomplete anti-viroid defenses and suppress viroid accumulation during the early stages of an infection. The replication of a highly-structured dsRNA-like hairpin RNA from a viroid genome serves as a PAMP and activates RNA-silencing targeting viroids. As a result, PSTVd-tolerant tomato cultivars, such as 'Moneymaker', continue to grow almost normally and show very few symptoms of disease. In contrast, the hpDCL2/4i-Moneymaker tomato line failed to defend initial viroid infection via RNA silencing, and as a result, allowed more aggressive replication and/or accumulation of viroids, which seemed to trigger excessive ROS production. Even in the PSTVd-tolerant tomato cultivar, our results indicated that, once the normal expression or function of DCL2s and DCL4 was destroyed, an unusually high state of expression emerged in stress-responsive miR398 and miR398a-3p, even after plants were infected with PSTVd and excessive amounts of ROS were generated. This abnormal situation, of course, leads to the inherently undesirable suppression of SOD mRNAs at the post-transcriptional level, impairing ROS-scavenging activity, and resulting in the development of severe systemic necrosis ultimately leading to plant death.

The production of ROS is an important defense reaction against pathogens that is rapidly induced upon recognition of a pathogen attack. Recent data from comprehensive and global transcriptome and metabolome analyses suggested that viroid infections trigger plant immune responses and result in the activation of various signaling pathways and associated activities, such as MAPK3, PR1, 1,3-beta-glucanase, and ROS biogenesis $[10,72,79,80]$. On the other hand, ROS are harmful substances that can cause significant damage to cell structures. Therefore, the proper management of ROS production and scavenging is very important when plants are protecting themselves against pathogen attacks. The results presented in this study identified several key factors (i.e., miR398, miR398a-3p, $\mathrm{Cu} / \mathrm{Zn}-\mathrm{SOD} 1$ and 2, CCS1, and ROS) in tomato plants which are responsible for causing necrosis, one of the most typical and serious disease symptoms induced by viroid infections, and revealed the existence of an unresolved relationship between DCLs, a key factor in RNA silencing against viroids, and the cell mechanism used to control ROS biogenesis. PSTVd-sensitive tomato cultivars, such as 'Rutgers', often develop various degrees of leaf and/or vein-necrosis, especially following infection by severe and lethal strains of PSTVd, CEVd, or tomato apical stunt viroid [81,82]. The observations presented here probably represent a general phenomenon that occurs in viroid-host interactions. Further elucidation of the molecular mechanisms underlying the development of viroid-induced necrosis will provide useful information with which it is possible to protect plants from severe damage resulting from viroid infections.

Supplementary Materials: The following are available online at http://www.mdpi.com/1999-4915/11/4/344/s1, Figure S1: Detection of transgene, transgene transcript, and transgene-derived siRNAs from three transgenic lines (51-6, 72E, and 82a) and control line (EC), Figure S2: Primary symptoms associated with potato spindole tubre viroid (PSTVd) infection in the DCL2/4i-72E and 82a Moneymaker tomato line, Figure S3: Northern-blot hybridization analysis to monitor the levels of potato spindle tuber viroid (PSTVd) accumulation in DCL2/4i-51-6, $72 \mathrm{E}$, and 82a lines, Figure S4: RT-qPCR analysis of endogenous SIDCL2b, 2c, and $2 d$ mRNAs in line 72E and EC before or after infection of potato spindle tuber viroid (PSTVd), Figure S5: Histograms of the number of potato spindle tuber viriod (PSTVd)-sRNA reads in 72E and EC (Emp in the figure), Figure S6: A comparison of hotspot pattern, Figure S7: In silico analysis of tomato miR398 and miR398a-3p target genes by psRNATarget software, Table S1: Names and sequences of PCR primers, Table S2: Relative ROS production and relative ROS scavenging activity of the 5 th and $7-8$ th true leaves.

Author Contributions: For research articles with several authors, a short paragraph specifying their individual contributions must be provided. The following statements should be used "Conceptualization, T.S.; Software, A.T.; Formal Analysis, T.S.; Investigation, T.S., S.I., A.K., M.F., K.S. and M.O.; Resources, A.K. and H.M.; Writing-Original Draft Preparation, T.S.; Writing-Review \& Editing, T.S.; Funding Acquisition, T.S.", please turn to the CRediT 
taxonomy for the term explanation. Authorship must be limited to those who have contributed substantially to the work reported.

Funding: This study was supported in part by Japan Society for the Promotion of Science (JSPS) KAKENHI grant no. $15 \mathrm{H} 04455$ and $18 \mathrm{H} 0221$ to T.S.

Acknowledgments: We thank Robert A Owens (USDA/ARS, MPPL, USA) and Adkar-Purushothama Charith Raj (RNA Group/Groupe ARN, Université de Sherbrooke, Canada; 2MYM Nutraceuticals Inc., 1500-409 Granville Street, Vancouver, BC V6C 1T2, Canada) for critical reading and valuable suggestions on the manuscript. The authors would like to thank Enago (www.enago.jp) for the English language review.

Conflicts of Interest: The authors declare no conflict of interest.

\section{References}

1. Diner, T.O. Potato spindle tuber "virus": IV. A replicating, low molecular weight RNA. Virology 1971, 45, 411-428. [CrossRef]

2. Di Serio, F.; Flores, R.; Verhoeven, J.T.J.; Li, S.-F.; Pallás, V.; Randles, W.J.; Sano, T.; Vidalakis, G.; Owens, R.A. Current status of viroid taxonomy. Arch. Virol. 2014, 159, 3467-3478. [CrossRef]

3. Ding, B.; Wang, Y. Viroids: Uniquely simple and tractable models to elucidate regulation of cell-to-cell trafficking of RNAs. DNA Cell. Biol. 2009, 28, 51-56. [CrossRef]

4. Diener, T.O. Biological properties. In The Viroids; Plenum: New York, NY, USA, 1987; Chapter 1; pp. 9-35.

5. Verhoeven, J.T.J.; Jansen, C.C.C.; Willemen, T.M.; Kox, L.F.F.; Owens, R.A.; Roenhorst, J.W. Natural infections of tomato by Citrus exocortis viroid, Columnea latent viroid, Potato spindle tuber viroid and Tomato chlorotic dwarf viroid. Eur. J. Plant Pathol. 2004, 110, 823-831. [CrossRef]

6. Verhoeven, J.T.J.; Botermans, M.; Meekes, E.T.M.; Roenhorst, J.W. Tomato apical stunt viroid in the Netherlands: Most prevalent pospiviroid in ornamentals and first outbreak in tomatoes. Eur. J. Plant Pathol. 2012, 133, 803-810. [CrossRef]

7. Tsushima, T.; Murakami, S.; Ito, H.; He, Y.-H.; Sano, T. Molecular characterization of potato spindle tuber viroid in dahlia. J. Gen. Plant Pathol. 2011, 77, 253-256. [CrossRef]

8. Tsuda, S.; Sano, T. Threats to Japanese agriculture from newly emerged plant viruses and viroids. J. Gen. Plant Pathol. 2014, 80, 2-14. [CrossRef]

9. Wang, Y.; Shibuya, M.; Taneda, A.; Kurauchi, T.; Senda, M.; Owens, R.A.; Sano, T. Accumulation of Potato spindle tuber viroid-specific small RNAs is accompanied by specific changes in gene expression in two tomato cultivars. Virology 2011, 413, 72-83. [CrossRef]

10. Owens, R.A.; Tech, K.B.; Shao, J.Y.; Sano, T.; Baker, C.J. Global analysis of tomato gene expression during potato spindle tuber viroid infection reveals a complex array of changes affecting hormone signaling. Mol. Plant Microbe Interact. 2012, 25, 582-598. [CrossRef]

11. Tsushima, D.; Tsushima, T.; Sano, T. Molecular dissection of a dahlia isolate of potato spindle tuber viroid inciting a mild symptoms in tomato. Virus Res. 2016, 214, 11-18. [CrossRef]

12. Dou, D.; Zhou, J.M. Phytopathogen effectors subverting host immunity: Different foes, similar battleground. Cell Host Microbe 2012, 12, 484-495. [CrossRef]

13. Martínez de Alba, A.E.; Elvira-Matelot, E.; Vaucheret, H. Gene silencing in plants: A diversity of pathways. Biochim. Biophys. Acta 2013, 1829, 1300-1308. [CrossRef]

14. Molnar, A.; Melnyk, C.; Baulcombe, D.C. Silencing signals in plants: A long journey for small RNAs. Genome Biol. 2011, 12, 215. [CrossRef]

15. Liu, L.; Chen, X. RNA quality control as a key to suppressing RNA silencing of endogenous genes in plants. Mol. Plant 2016, 9, 826-836. [CrossRef]

16. Itaya, A.; Folimonov, A.; Matsuda, Y.; Nelson, R.S.; Ding, B. Potato spindle tuber viroid as inducer of RNA silencing in infected tomato. Mol. Plant Microbe Interact. 2001, 14, 1332-1334. [CrossRef]

17. Papaefthimiou, I.; Hamilton, A.J.; Denti, M.A.; Baulcombe, D.C.; Tsagris, M.; Tabler, M. Replicating potato spindle tuber viroid RNA is accompanied by short RNA fragments that are characteristic of posttranscriptional gene silencing. Nucleic Acids Res. 2001, 29, 2395-2400. [CrossRef] 
18. Itaya, A.; Zhong, X.; Bundschuh, R.; Qi, Y.; Wang, Y.; Takeda, R.; Harris, A.R.; Molina, C.; Nelson, R.S.; Ding, B. A structured viroid RNA serves as a substrate for dicer-like cleavage to produce biologically active small RNAs but is resistant to RNA-induced silencing complex-mediated degradation. J. Virol. 2007, 81, 2980-2994. [CrossRef]

19. Machida, S.; Yamahata, N.; Watanuki, H.; Owens, R.A.; Sano, T. Successive accumulation of two size classes of viroid-specific small RNAs in potato spindle tuber viroid-infected tomato plants. J. Gen. Virol. 2007, 88, 3452-3457. [CrossRef]

20. Dadami, E.; Boutla, A.; Vrettos, N.; Tzortzakaki, S.; Karakasilioti, I.; Kalantidis, K. DICER-LIKE 4 but not DICER-LIKE 2 may have a positive effect on potato spindle tuber viroid accumulation in Nicotiana benthamiana. Mol. Plant 2013, 6, 232-234. [CrossRef]

21. Katsarou, K.; Mavrothalassiti, E.; Dermauw, W.; Leeuwen, T.V.; Kalantidis, K. Combined activity of DCL2 and DCL3 is crucial in the defense against potato spindle tuber viroid. PLoS Pathog. 2016, 12, e1005936. [CrossRef]

22. Martínez de Alba, A.E.; Flores, R.; Hernández, C. Two chloroplastic viroids induce the accumulation of small RNAs associated with posttranscriptional gene silencing. J. Virol. 2002, 76, 13094-13096. [CrossRef]

23. Di Serio, F.; Gisel, A.; Navarro, B.; Delgado, S.; Martínez de Alba, A.E.; Donvito, G.; Flores, R. Deep sequencing of the small RNAs derived from two symptomatic variants of a chloroplastic viroid: Implications for their genesis and for pathogenesis. PLoS ONE 2009, 4, 7539. [CrossRef]

24. Bolduc, F.; Hoareau, C.; St-Pierre, P.; Perreault, J.P. In-depth sequencing of the siRNAs associated with peach latent mosaic viroid infection. BMC Mol. Biol. 2010, 11, 16. [CrossRef]

25. Minoia, S.; Carbonell, A.; Di Serio, F.; Gisel, A.; Carrington, J.C.; Navarro, B.; Flores, R. Specific argonautes selectively bind small RNAs derived from potato spindle tuber viroid and attenuate viroid accumulation in vivo. J. Virol. 2014, 88, 11933-11945. [CrossRef]

26. Gómez, G.; Martínez, G.; Pallás, V. Viroid-induced symptoms in Nicotiana benthamiana plants are dependent on RDR6 activity. Plant Physiol. 2008, 148, 414-423. [CrossRef]

27. Di Serio, F.; Martínez de Alba, A.E.; Navarro, B.; Gisel, A.; Flores, R. RNA-dependent RNA polymerase 6 delays accumulation and precludes meristem invasion of a viroid that replicates in the nucleus. J. Virol. 2010, 84, 2477-2489. [CrossRef]

28. Adkar-Purushothama, C.R.; Kasai, A.; Sugawara, K.; Yamamoto, H.; Yamazaki, Y.; He, Y.-H.; Takada, N.; Goto, H.; Shindo, S.; Harada, T.; et al. RNAi mediated inhibition of viroid infection in transgenic plants expressing viroid-specific small RNAs derived from various functional domains. Sci. Rep. 2015, 5, 17949. [CrossRef]

29. Carbonell, A.; Martínez de Alba, A.E.; Flores, R.; Gago, S. Double-stranded RNA interferes in a sequencespecific manner with the infection of representative members of the two viroid families. Virology 2008, 371, 44-53. [CrossRef]

30. Dalakouras, A.; Dadami, E.; Wassenegger, M. Engineering viroid resistance. Viruses 2015, 7, $634-646$. [CrossRef]

31. Kasai, A.; Sano, T.; Harada, T. Scion on a stock producing siRNAs of potato spindle tuber viroid (PSTVd) attenuates accumulation of the viroid. PLoS ONE 2013, 8, e57736. [CrossRef]

32. Schwind, N.; Zwiele, M.; Itaya, A.; Ding, B.; Wang, M.; Krczal, G.; Wassenegger, M. RNAi-mediated resistance to Potato spindle tuber viroid in transgenic tomato expressing a viroid hairpin RNA construct. Plant Pathol. 2009, 10, 459-469.

33. Adkar-Purushothama, C.R.; Brosseau, C.; Giguère, T.; Sano, T.; Moffett, P.; Perreault, J.P. Small RNA derived from the virulence modulating region of the potato spindle tuber viroid silences callose synthase genes of tomato plants. Plant Cell 2015, 27, 2178-2194. [CrossRef]

34. Adkar-Purushothama, C.R.; Iyer, P.; Perreault, J.P. Potato spindle tuber viroid infection triggers degradation of chloride channel protein CLC-b-like and ribosomal protein S3a-like mRNAs in tomato plants. Sci. Rep. 2017, 7, 8341. [CrossRef]

35. Adkar-purushothama, C.R.; Sano, T.; Perreault, J.P. Viroid-derived small RNA induces early flowering in tomato plants by RNA silencing. Mol. Plant Pathol. 2018, 19, 2446-2458. [CrossRef]

36. Avina-Padilla, K.; Martinez de la Vega, O.; Rivera-Bustamante, R.; Martinez-Soriano, J.P.; Owens, R.A.; Hammond, R.W.; Vielle-Calzada, J.P. In silico prediction and validation of potential gene targets for pospiviroid-derived small RNAs during tomato infection. Gene 2015, 564, 197-205. [CrossRef] 
37. Eamens, A.L.; Smith, N.A.; Dennis, E.S.; Wassenegger, M.; Wang, M.B. In Nicotiana species, an artificial microRNA corresponding to the virulence modulating region of potato spindle tuber viroid directs RNA silencing of a soluble inorganic pyrophosphatase gene and the development of abnormal phenotypes. Virology 2014, 450-451, 266-277. [CrossRef]

38. Markarian, N.; Li, H.W.; Ding, S.W.; Semancik, J.S. RNA silencing as related to viroid induced symptom expression. Arch. Virol. 2004, 149, 397-406. [CrossRef]

39. Mishra, A.K.; Duraisamy, G.S.; Matoušekm, J.; Radisek, S.; Javornik, B.; Jakse, J. Identification and characterization of microRNAs in Humulus lupulus using high-throughput sequencing and their response to Citrus bark cracking viroid (CBCVd) infection. BMC Genom. 2016, 17, 919. [CrossRef]

40. Navarro, B.; Gisel, A.; Rodio, M.E.; Degado, S.; Flores, R.; Di Serio, F. Small RNAs containing the pathogenic determinant of a chloroplast-replicating viroid guide the degradation of a host mRNA as predicted by RNA silencing. Plant J. 2012, 70, 991-1003. [CrossRef]

41. Thibaut, O.; Claude, B. Innate immunity activation and RNAi interplay in citrus exocortis viroid-Tomato pathosystem. Viruses 2018, 10, 587. [CrossRef]

42. Wang, M.B.; Bian, X.Y.; Wu, L.M.; Liu, L.X.; Smith, N.A.; Isenegger, D.; Wu, R.M.; Masuta, C.; Vance, V.B.; Watson, J.M.; et al. On the role of RNA silencing in the pathogenicity and evolution of viroids and viral satellites. Proc. Natl. Acad. Sci. USA 2004, 101, 3275-3280. [CrossRef]

43. Bernstein, E.; Caudy, A.A.; Hammond, S.M.; Hannon, G.J. Role for a bidentate ribonuclease in the initiation step of RNA interference. Nature 2001, 409, 363. [CrossRef] [PubMed]

44. Liu, Q.; Feng, Y.; Zhu, Z. Dicer-like (DCL) proteins in plants. Funct. Integr. Genom. 2009, 9, $277-286$. [CrossRef]

45. Bartel, D.P. MicroRNAs: Genomics, biogenesis, mechanism, and function. Cell 2004, 116, 281-297. [CrossRef]

46. Ramachandran, V.; Chen, X. Small RNA metabolism in Arabidopsis. Trends Plant Sci. 2008, 13, 368-374. [CrossRef] [PubMed]

47. Xie, M.; Zhang, S.; Yu, B. microRNA biogenesis, degradation and activity in plants. Cell. Mol. Life Sci. 2014, 72, 87-99. [CrossRef]

48. Xie, Z.; Johansen, L.K.; Gustafson, A.M.; Kasschau, K.D.; Lellis, A.D.; Zilberman, D.; Jacobsen, S.E.; Carrington, J.C. Genetic and functional diversification of small RNA pathways in plants. PLoS Biol. 2004, 2, 642-652. [CrossRef]

49. Borsani, O.; Zhu, J.; Verslues, P.E.; Sunkar, R.; Zhu, J.K. Endogenous siRNAs derived from a pair of natural cis-antisense transcripts regulate salt tolerance in Arabidopsis. Cell 2005, 123, 1279-1291. [CrossRef]

50. Gasciolli, V.; Mallory, A.C.; Bartel, D.P.; Vaucheret, H. Partially redundant functions of Arabidopsis DICER-like enzymes and a role for DCL4 in producing trans-acting siRNAs. Curr. Biol. 2005, 15, 1494-1500. [CrossRef]

51. Mlotshwa, S.; Pruss, G.J.; Peragine, A.; Endres, M.W.; Li, J.; Chen, X.; Poethig, R.S.; Bowman, L.H.; Vance, V. DICER-LIKE2 plays a primary role in transitive silencing of transgenes in Arabidopsis. PLoS ONE 2008, 3, e1755. [CrossRef]

52. Bouché, N.; Lauressergues, D.; Gasciolli, V.; Vaucheret, H. An antagonistic function for Arabidopsis DCL2 in development and a new function for DCL4 in generating viral siRNAs. EMBO J. 2006, 25, 3347-3356. [CrossRef]

53. Vazquez, F.; Blevins, T.; Ailhas, J.; Boller, T.; Meins, F. Evolution of Arabidopsis MIR genes generates novel microRNA classes. Nucleic Acids Res. 2008, 36, 6429-6438. [CrossRef]

54. Xie, Z.; Allen, E.; Wilken, A.; Carrington, J.C. DICER-LIKE 4 functions in trans-acting small interfering RNA biogenesis and vegetative phase change in Arabidopsis thaliana. Proc. Natl. Acad. Sci. USA 2005, 102, 12984-12989. [CrossRef]

55. Dunoyer, P.; Voinnet, O. The complex interplay between plant viruses and host RNA-silencing pathways. Curr. Opin. Plant Biol. 2005, 8, 415-423. [CrossRef]

56. Rajagopalan, R.; Vaucheret, H.; Trejo, J.; Bartel, D.P. A diverse and evolutionarily fluid set of microRNAs in Arabidopsis thaliana. Genes Dev. 2006, 20, 3407-3425. [CrossRef]

57. Vazquez, F.; Vaucheret, H.; Rajagopalan, R.; Lepers, C.; Gasciolli, V.; Mallory, A.C.; Hilbert, J.L.; Bartel, D.P.; Crété, P. Endogenous transacting siRNAs regulate the accumulation of Arabidopsis mRNAs. Mol. Cell 2004, 16, 69-79. [CrossRef]

58. Duc, C.; Sherstnev, A.; Cole, C.; Barton, G.J.; Simpson, G.G. Transcription termination and chimaera RNA formation controlled by Arabidopsis thaliana FPA. PLoS Genet. 2013, 9, e1003867. [CrossRef] 
59. Liu, F.; Bakht, S.; Dean, C. Cotranscriptional role for Arabidopsis DICER-LIKE 4 in transcription termination. Science 2012, 335, 1621-1623. [CrossRef]

60. Deleris, A.; Gallego-Bartolome, J.; Bao, J.; Kasschau, K.D.; Carrington, J.C.; Voinnet, O. Hierarchical action and inhibition of plant Dicer-like proteins in antiviral defense. Science 2006, 313, 68-71. [CrossRef]

61. Zhang, C.; Wu, Z.; Wu, J. Biogenesis, function, and applications of virus-derived small RNAs in plants. Front. Microbiol. 2015, 6, 1-12. [CrossRef]

62. Fusaro, A.F.; Matthew, L.; Smith, N.A.; Curtin, S.J.; Dedic-Hagan, J.; Ellacott, G.A. RNA interference inducing hairpin RNAs in plants act through the viral defence pathway. EMBO Rep. 2006, 7, 1168-1175. [CrossRef]

63. Beauclair, L.; Yu, A.; Bouché, N. microRNA-directed cleavage and translational repression of the copper chaperone for superoxide dismutase mRNA in Arabidopsis. Plant J. 2010, 62, 454-462. [CrossRef] [PubMed]

64. Ohta, S.; Mita, S.; Hattori, T.; Nakamura, K. Construction and expression in tobacco of a $\beta$-glucuronidase (GUS) reporter gene containing an intron within the coding sequence. Plant Cell Physiol. 1990, 31, 805-813.

65. Murray, M.G.; Thompson, W.F. Rapid isolation of high molecular weight plant DNA. Nucleic Acids Res. 1980, 8, 4321-4325. [CrossRef] [PubMed]

66. Feng, K.; Yu, J.; Cheng, Y.; Ruan, M.; Wang, R.; Ye, Q.; Zhou, G.; Li, Z.; Yao, Z.; Yang, Y.; et al. The SOD gene family in tomato: Identification, phylogenetic relationships, and expression patterns. Front. Plant Sci. 2016, 7, 1279. [CrossRef] [PubMed]

67. Chen, C.; Ridzon, D.A.; Broomer, A.J.; Zhou, Z.; Danny, H.; Lee, D.H.; Nguyen, J.T.; Barbisin, M.; Xu, N.L.; Mahuvakar, V.R.; et al. Real-time quantification of microRNAs by stem-loop RT-PCR. Nucleic Acids Res. 2005, 33, e179. [CrossRef]

68. Suzuki, T.; Fujibayashi, M.; Hataya, T.; Taneda, A.; He, Y.H.; Tsushima, T.; Duraisamy, G.S.; Siglová, K.; Matoušek, J.; Sano, T. Characterization of host-dependent mutations of apple fruit crinkle viroid replicating in newly identified experimental hosts suggests maintenance of stem-loop structures in the left-hand half of the molecule is important for replication. J. Gen. Virol. 2017, 98, 506-516. [CrossRef] [PubMed]

69. Spitzer, M.; Wildenhain, J.; Rappsilber, J.; Tyers, M. BoxPlotR: A web tool for generation of box plots. Nat. Methods 2014, 11, 121-122. [CrossRef] [PubMed]

70. Tsushima, D.; Adkar-Purushothama, C.R.; Taneda, A.; Sano, T. Changes in relative expression levels of viroid-specific small RNAs and microRNAs in tomato plants infected with severe and mild symptom-inducing isolates of Potato spindle tuber viroid. J. Gen. Plant Pathol. 2015, 81, 49-62. [CrossRef]

71. Sunkar, R.; Kapoor, A.; Zhu, J.-K. Posttranscriptional induction of two Cu/Zn superoxide dismutase genes in Arabidopsis is mediated by downregulation of miR398 and important for oxidative stress tolerance. Plant Cell 2006, 18, 2051-2065. [CrossRef]

72. Bagherian, A.A.A.; Hamzehzarghani, H.; Izadpanah, K.; Djavaheri, M. Effects of potato spindle tuber viroid infection on tomato metabolic profile. J. Plant Physiol. 2016, 201, 42-53. [CrossRef]

73. Zhu, H.; Zhou, Y.; Castillo-González, C.; Lu, A.; Ge, C.; Zhao, Y.T.; Duan, L.; Li, Z.; Axtell, M.J.; Wang, X.J.; et al. Bidirectional processing of pri-miRNAs with branched terminal loops by Arabidopsis Dicer-like1. Nat. Struct. Mol. Biol. 2013, 20, 1106-1115. [CrossRef]

74. Hill, J.M.; Lukiw, W.J. Comparing miRNAs and viroids; highly conserved molecular mechanisms for the transmission of genetic information. Front. Cell Neurosci. 2014, 8, 45. [CrossRef]

75. Hill, J.M.; Zhao, Y.; Bhattacharjee, S.; Lukiw, W.J. miRNAs and viroids utilize common strategies in genetic signal transfer. Front. Mol. Neurosci. 2014, 7, 10. [CrossRef]

76. Campos, L.; Granell, P.; Tárraga, S.; López-Gresa, P.; Conejero, V.; Bellés, J.M.; Rodrigo, I.; Lisón, P. Salicylic acid and gentisic acid induce RNA silencing-related genes and plant resistance to RNA pathogens. Plant Physiol. Biochem. 2014, 77, 35-43. [CrossRef]

77. Juszczak, I.; Baier, M. The strength of the miR398-Csd2-CCS1 regulon is subject to natural variation in Arabidopsis thaliana. FEBS Lett. 2012, 586, 3385-3390. [CrossRef]

78. Ren, L.; Guiliang, T.G. Identification of sucrose-responsive microRNAs reveals sucrose-regulated copper accumulations in an SPL7-dependent and independent manner in Arabidopsis thaliana. Plant Sci. 2012, 187, 59-68. [CrossRef]

79. Zheng, Y.; Wang, Y.; Ding, B.; Fei, Z. Comprehensive transcriptome analyses reveal that potato spindle tuber viroid triggers genome-wide changes in alternative splicing, inducible trans-acting activity of phased secondary small interfering RNAs, and immune responses. J. Virol. 2017, 91, e00247-17. [CrossRef] 
80. Xia, C.; Li, S.; Hou, W.; Fan, Z.; Xiao, H.; Lu, M.; Sano, T.; Zhang, Z. Global transcriptomic changes induced by infection of cucumber (Cucumis sativus L.) with mild and severe variants of hop stunt viroid. Front. Microbiol. 2017, 8, 2427. [CrossRef]

81. Schnölzer, M.; Haas, B.; Ramm, K.; Hofmann, H.; Sänger, H.L. Correlation between structure and pathogenicity of potato spindle tuber viroid (PSTV). EMBO J. 1985, 4, 2181-2190. [CrossRef]

82. Sano, T.; Candresse, T.; Hammond, R.W.; Diener, T.O.; Owens, R.A. Identification of multiple structural domains regulating viroid pathogenicity. Proc. Natl. Acad. Sci. USA 1992, 89, 10104-10108. [CrossRef] [PubMed]

(C) 2019 by the authors. Licensee MDPI, Basel, Switzerland. This article is an open access article distributed under the terms and conditions of the Creative Commons Attribution (CC BY) license (http://creativecommons.org/licenses/by/4.0/). 